\title{
A model for predicting changes in the electrical conductivity, practical salinity, and absolute salinity of seawater due to variations in relative chemical composition
}

\author{
R. Pawlowicz \\ Dept. of Earth and Ocean Sciences, University of British Columbia, Canada \\ Received: 3 November 2009 - Published in Ocean Sci. Discuss.: 27 November 2009 \\ Revised: 12 March 2010 - Accepted: 12 March 2010 - Published: 18 March 2010
}

\begin{abstract}
Salinity determination in seawater has been carried out for almost 30 years using the Practical Salinity Scale 1978. However, the numerical value of so-called practical salinity, computed from electrical conductivity, differs slightly from the true or absolute salinity, defined as the mass of dissolved solids per unit mass of seawater. The difference arises because more recent knowledge about the composition of seawater is not reflected in the definition of practical salinity, which was chosen to maintain historical continuity with previous measures, and because of spatial and temporal variations in the relative composition of seawater. Accounting for these spatial variations in density calculations requires the calculation of a correction factor $\delta S_{\mathrm{A}}$, which is known to range from 0 to $0.03 \mathrm{~g} \mathrm{~kg}^{-1}$ in the world oceans. Here a mathematical model relating compositional perturbations to $\delta S_{\mathrm{A}}$ is developed, by combining a chemical model for the composition of seawater with a mathematical model for predicting the conductivity of multi-component aqueous solutions. Model calculations for this estimate of $\delta S_{\mathrm{A}}$, denoted $\delta S_{\mathrm{R}}^{\text {soln }}$, generally agree with estimates of $\delta S_{\mathrm{A}}$ based on fits to direct density measurements, denoted $\delta S_{\mathrm{R}}^{\text {dens }}$, and show that biogeochemical perturbations affect conductivity only weakly. However, small systematic differences between model and density-based estimates remain. These may arise for several reasons, including uncertainty about the biogeochemical processes involved in the increase in Total Alkalinity in the North Pacific, uncertainty in the carbon content of IAPSO standard seawater, and uncertainty about the haline contraction coefficient for the constituents involved in bio-
\end{abstract}

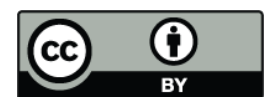

Correspondence to: R. Pawlowicz (rich@eos.ubc.ca) geochemical processes. This model may then be important in constraining these processes, as well as in future efforts to improve parameterizations for $\delta S_{\mathrm{A}}$.

\section{Introduction}

Procedures for routine estimation of the salinity of seawater have been standardized for nearly 30 years. These procedures are based on combining measurements of the electrical conductivity $\kappa$ of the water with a purely empirical equation relating conductivity and a so-called practical salinity $S_{\mathrm{P}}$ :

$S_{\mathrm{P}}=f_{78}(\kappa)$

The equation $f_{78}(\cdot)$ is specified by the Practical Salinity Scale 1978, denoted PSS-78 (UNESCO, 1981), with a lowsalinity correction (Hill et al., 1986a) that extends the range of validity down to near-zero salinities. Temperature and pressure are also important factors in these equations but are omitted from the notation used here. Note also that practical considerations add some complexity to this brief description of PSS-78.

It was clearly recognized at the time PSS-78 was adopted that the utility of the computed salinities depended on two factors. First, it was necessary that the relative chemical composition of seawater would be constant throughout the world's oceans. Thus waters of the same salinity would have the same conductivity and vice versa. It was known that there were (and are) spatial variations in the composition, but investigations suggested that the numerical effects on salinity estimates arising from these variations remained within limits acceptable to the research standards of the day (Lewis and Perkin, 1978; Hill et al., 1986b). Second, it required a

Published by Copernicus Publications on behalf of the European Geosciences Union. 
Table 1. List of important symbols and abbreviations.

\begin{tabular}{ll}
\hline$C_{*}$ & Chemical composition of standard seawater \\
$C_{0}$ & Chemical composition of standard seawater when $S_{\mathrm{P}}=35$. \\
$c_{i}$ & Concentration $\left(\mathrm{mol} \mathrm{kg}^{-1}\right)$ of $i$ th constituent of seawater \\
$c_{i}^{*}$ & Concentration $\left(\mathrm{mol} \mathrm{L}^{-1}\right.$ ) of $i$ th constituent of seawater \\
$\delta C_{*}$ & Small composition perturbation (added to $C_{*}$ ) \\
$\delta S_{\mathrm{P}}$ & Practical Salinity change resulting from compositional perturbation \\
$\delta S_{\mathrm{P}}^{*}$ & Simpler estimate of Practical Salinity change resulting from compositional perturbation \\
$\delta S_{*}^{\text {soln }}$ & Absolute salinity change resulting from compositional perturbation \\
$\delta S_{\mathrm{R}}^{\text {soln}(1)}$ & Salinity correction estimated using fixed chlorinity calculation \\
$\delta S_{\mathrm{R}}^{\text {soln}}(2)$ & Salinity correction estimated using fixed conductivity calculation \\
$\delta S_{\mathrm{R}}^{\text {dens }}$ & Estimate of salinity correction based on density (e.g., McDougall et al., 2009) \\
$\epsilon$ & relative error of Pa08 prediction \\
$I^{*}$ & Ionic strength (mol L-1) \\
$I_{m}$ & Ionic strength (mol kg \\
$\kappa$ & True conductivity \\
$\kappa_{\mathrm{Pa} 08}$ & Conductivity estimated using Pa08 \\
$\lambda_{i}^{\circ}$ & infinite dilution ionic equivalent conductivity \\
$\lambda_{i}$ & ionic equivalent conductivity \\
$M_{i}$ & Molar mass of $i$ th constituent of seawater \\
$\mathrm{M} 08$ & Chemical model of seawater in Millero et al. (2008) \\
$\mathrm{Pa} 08$ & Conductivity model described by Pawlowicz (2008) \\
$\rho$ & Density of seawater \\
$S_{\mathrm{P}}$ & Practical salinity \\
$S_{\mathrm{A}}^{\text {soln }}$ & Absolute salinity \\
$S_{\mathrm{A}}^{\mathrm{dens}}$ & Absolute salinity using procedure of Millero et al. (2008); McDougall et al. (2009) \\
$S_{\mathrm{R}}$ & Reference salinity (Millero et al., 2008) \\
$\mathrm{SSW}$ & IAPSO Standard Seawater \\
$\mathrm{SSW}$ & Chemical model for SSW circa 1976 in this work \\
$z_{i}$ & Valence of $i$ th constituent of seawater \\
\hline &
\end{tabular}

method by which different investigators could intercalibrate their measurements. Procedures providing "standard" seawater from a single source for calibrating chlorinity titrations were adapted to provide batches of labelled IAPSO standard seawater (SSW) for conductivity calibrations; PSS-78 itself is based primarily on measurements of SSW batches P73, P75, and P79 (Perkin and Lewis, 1980).

However, there is a small numerical difference between the computed practical salinity $S_{\mathrm{P}}$ of seawater and its true or absolute salinity $S_{\mathrm{A}}^{\text {soln }}$ in $\mathrm{g} \mathrm{kg}^{-1}$, defined as the mass of solids dissolved in solution per unit mass of seawater, i.e.:

$S_{\mathrm{A}}^{\mathrm{soln}}=s(C)=\sum_{i=1}^{N_{c}} M_{i} c_{i}$

where $M_{i}$ (Table 2) is the molar mass of the $i$ th of $N_{c}$ components of seawater (not including dissolved gases), and $C=\left\{c_{1}, c_{2}, \ldots, c_{i}, ..\right\}$ is a vector of the corresponding concentrations. This difference arises for historical reasons (see, e.g., Millero et al., 2008, for more details). For SSW this difference can be accounted for by a simple scaling
$S_{\mathrm{R}}=\gamma S_{\mathrm{P}}$

where $\gamma$ incorporates updated knowledge of the true chemical composition of SSW, and $S_{\mathrm{R}}$ is the reference salinity, i.e., the absolute salinity of SSW with the measured conductivity. However, for real ocean waters there are also small spatial and temporal differences in the relationship arising from small variations in the relative chemical composition of seawater. Thus in general:

$S_{\mathrm{A}}^{\text {soln }}=S_{\mathrm{R}}+\delta S_{\mathrm{R}}^{\text {soln }}$

The salinity anomaly $\delta S_{\mathrm{R}}^{\text {soln }}$ has previously been denoted $\delta S_{\mathrm{A}}$ (Millero et al., 2008), and is in the range of 0 to $0.03 \mathrm{~g} \mathrm{~kg}^{-1}$ in the open ocean, with largest values in the North Pacific (McDougall et al., 2009), and can be as large as $0.05 \mathrm{~g} \mathrm{~kg}^{-1}$ in some estuarine waters (Millero, 1984). It should be zero by definition when measurements are made of SSW.

In recent years the increasing number of high-quality conductivity measurements of seawater on global scales has led to the realization that these spatio-temporal differences may 
Table 2. Model parameters including molar masses $M_{i}$, infinite dilution equivalent conductivities $\lambda_{i}^{\circ}$, ionic equivalent conductivities $\bar{\lambda}_{i}$ in SSW76, conductivities per unit mass $\psi_{i}$, and coefficients multiplying $\delta c_{i}$ in the approximate $\delta S_{\mathrm{R}}^{\text {soln }} \mathrm{Eq}$. (30).

\begin{tabular}{|c|c|c|c|c|c|c|}
\hline Species & $\begin{array}{r}M_{i} \\
{\left[\mathrm{~g} \mathrm{~mol}^{-1}\right]}\end{array}$ & $\begin{array}{c}\lambda_{i}^{\circ} \\
{\left[\mathrm{mS} \mathrm{cm}^{-}\right.}\end{array}$ & $\begin{array}{r}\bar{\lambda}_{i} \\
\left.\left(\mathrm{~mol} \mathrm{~L}^{-1}\right)^{-1}\right]\end{array}$ & {$\left[\mathrm{mS} \mathrm{cm}^{-1}\left(\mathrm{~g} \mathrm{~kg}^{-1}\right)^{-1}\right]$} & $\begin{array}{r}1-\frac{\psi_{i}}{\bar{\psi}} \\
-\end{array}$ & $\begin{array}{r}M_{i}\left(1-\frac{\psi_{i}}{\bar{\psi}}\right) \\
\times 10^{-3}\end{array}$ \\
\hline $\mathrm{Na}^{+}$ & 22.9898 & 50.1 & 29.9 & 1.33 & 0.02 & 0.40 \\
\hline $\mathrm{Mg}^{2+}$ & 24.3050 & 53.0 & 20.5 & 1.73 & -0.28 & -6.78 \\
\hline $\mathrm{Ca}^{2+}$ & 40.0780 & 59.5 & 23.8 & 1.21 & 0.10 & 4.14 \\
\hline $\mathrm{K}^{+}$ & 39.0983 & 73.5 & 48.2 & 1.26 & 0.07 & 2.67 \\
\hline $\mathrm{Sr}^{2+}$ & 87.6200 & 59.4 & 24.3 & 0.57 & 0.58 & 50.88 \\
\hline $\mathrm{Cl}^{-}$ & 35.4530 & 76.3 & 50.1 & 1.45 & -0.07 & -2.43 \\
\hline $\mathrm{SO}_{4}^{2-}$ & 96.0626 & 80.0 & 33.5 & 0.71 & 0.47 & 45.38 \\
\hline $\mathrm{Br}^{-}$ & 79.9040 & 78.1 & 51.8 & 0.66 & 0.51 & 40.69 \\
\hline $\mathrm{F}^{-}$ & 18.9984 & 55.4 & 33.1 & 1.78 & -0.32 & -6.01 \\
\hline $\mathrm{HCO}_{3}^{-}$ & 61.0168 & 44.5 & 24.8 & 0.42 & 0.69 & 42.28 \\
\hline $\mathrm{CO}_{3}^{2-}$ & 60.0089 & 69.3 & 26.7 & 0.91 & 0.33 & 19.57 \\
\hline $\mathrm{B}(\mathrm{OH})_{3}$ & 61.8330 & - & - & - & 1.00 & 61.83 \\
\hline $\mathrm{B}(\mathrm{OH})_{4}^{-}$ & 78.8404 & 35.2 & 17.1 & 0.22 & 0.84 & 65.89 \\
\hline $\mathrm{CO}_{2}$ & 44.0095 & - & - & - & 1.00 & 44.01 \\
\hline $\mathrm{OH}^{-}$ & 17.0073 & 198.0 & 156.9 & 9.44 & -5.98 & -101.69 \\
\hline $\mathrm{H}^{+}$ & 1.0079 & 349.6 & 279.0 & 283.23 & -208.36 & -210.02 \\
\hline $\mathrm{NO}_{3}^{-}$ & 62.0049 & 71.4 & 43.9 & 0.73 & 0.46 & 28.77 \\
\hline $\mathrm{Si}(\mathrm{OH})_{4}$ & 96.1149 & - & - & - & 1.00 & 96.11 \\
\hline
\end{tabular}

have practical importance in understanding the global circulation. A reevaluation of the procedures for determining thermodynamic properties of seawater, including density, suggests that more accurate results can be obtained by returning to a procedure in which absolute salinity is used instead of $S_{\mathrm{P}}$ as a state variable (Feistel, 2008; Millero et al., 2008). In this procedure a best estimate $S_{\mathrm{R}}$ for the absolute salinity of SSW is made by taking $\gamma=u_{\mathrm{PS}} \equiv 35.16504 / 35 \approx 1.004715$. For non-standard seawaters an offset, which was also called $\delta S_{\mathrm{A}}$ (Millero et al., 2008) but is here denoted $\delta S_{\mathrm{R}}^{\mathrm{dens}}$ to indicate that it is found from measurements of density anomalies, is added to $S_{\mathrm{R}}$ to calculate $S_{\mathrm{A}}^{\text {dens }}$ as a best estimate for the absolute salinity (McDougall et al., 2009).

The absolute salinity can be directly estimated by measuring the density of water samples and then inverting the equation of state which relates density and salinity. The algorithm for $\delta S_{\mathrm{R}}^{\text {dens }}$ provided by McDougall et al. (2009) is based on a fit of such data against measured $\mathrm{Si}(\mathrm{OH})_{4}$ concentrations. Other algorithms for estimating $\delta S_{\mathrm{R}}^{\text {dens }}$ also exist (Brewer and Bradshaw, 1975; Millero, 2000). These are also based on purely empirical correlations of density anomalies with concentrations of specific chemical species, typically nutrients and components of the carbonate system.

However, little work has been done on understanding the full theoretical basis for these corrections. A complete chemical theory would include a model for seawater, and a method for determining the variations in conductivity and density that result from compositional variations. Density has been well-studied (e.g. Millero et al., 1976), but in spite of the practical importance of conductivity in ocean measurements there has been virtually no work done in developing a theory of electrical conductivity for natural seawaters. Recently, a model has been developed for calculating the electrical conductivity of natural freshwaters, based on their chemical composition (Pawlowicz, 2008, hereafter Pa08). Although the $\mathrm{Pa} 08$ model works well for waters of low salinities (less than a few $\mathrm{g} \mathrm{kg}^{-1}$ of dissolved solids), accuracy in waters of higher salinities is not sufficient to directly replace the empirical relationship specified by PSS-78. However, it will be shown here that the model can be used to quantitatively calculate the effects of small compositional variations on the known PSS-78 conductivity/salinity relationship.

The purpose of this paper is then twofold. First, to develop a seawater conductivity model, based on Pa08, capable of quantitatively determining the effects of small variations in the chemical composition of a model seawater on its conductivity, and consequently on $S_{\mathrm{P}}$. Second, to use this model to compute corrections $\delta S_{\mathrm{R}}^{\text {soln }}$ directly from a suitable set of observations of the concentrations of specific constituents of seawater, independent of density measurements. This model will then be a complement to the available empirical densitybased estimates $\delta S_{\mathrm{R}}^{\text {dens }}$. 


\section{Methods}

The general approach is based on modeling perturbations about a known base state for SSW. The base state consists of the known PSS-78 relationship (Eq. 1), and a chemical composition which is a function of the practical salinity.

The first step is then to construct the model composition $C_{*}$ for SSW, with an assumed practical salinity $S_{\mathrm{P} *}$, true conductivity $\kappa_{*}=f_{78}^{-1}\left(S_{\mathrm{P} *}\right)$, and computed reference salinity (via Eq. 2) $S_{*}=\gamma S_{\mathrm{P} *}$, which in this case equals the absolute salinity. The composition $C_{*}$ will be based on a model of the changes arising from dilutions and evaporations of a reference composition $C_{0}$ for which $S_{\mathrm{P}}=35$. Thus our seawater model will mimic the seawater used to develop PSS-78, and can be used to estimate $\gamma$.

The second step is to compute conductivity and absolute salinity perturbations, $\delta \kappa$ and $\delta S_{*}^{\text {soln }}$ respectively, arising from compositional changes. There are two kinds of calculation possible. The most straightforward occurs when an initial base state $C_{*}$ is known, and a known perturbation $\delta C_{*}$ is added. The Pa08 conductivity model is used to estimate $\delta \kappa$. In this calculation a nonzero offset $\delta S_{\mathrm{R}}^{\text {soln }}$ can arise because both absolute and conductivity-based reference salinities change (to values of $S_{\mathrm{A}}^{\text {soln }}$ and $S_{\mathrm{R}}$ respectively), but generally by different amounts. Since these situations often involve composition changes only in the nonconservative elements of seawater, we call this a constant chlorinity calculation. However, estuarine situations when freshwaters (which may contain $\mathrm{Cl}^{-}$and other so-called conservative elements) are added will also be handled in this way. Results can be simplified into an approximate analytical form, which can then be used to qualitatively understand the effect of perturbations.

In contrast, a more formally correct procedure for the correction of ocean measurements is to compute $\delta S_{\mathrm{R}}^{\text {soln }}$ when the composition is perturbed, but only the final conductivity $\kappa$ (and hence $S_{\mathrm{R}}$ ) are known. In this constant conductivity calculation the addition of a known concentration of (say) nitrate, which is ionic and would increase conductivity, would be balanced by a small dilution of the SSW composition corresponding to the measured $S_{\mathrm{R}}$, in order to keep conductivity constant. The $\mathrm{Pa} 08$ model is then used iteratively to calculate the dilution factor, such that the conductivity of final composition composed of diluted SSW plus the composition anomaly matches the measurement. A change $\delta S_{\mathrm{R}}^{\mathrm{soln}(2)}$ is found by subtracting the initial $S_{\mathrm{R}}$ from the absolute salinity of the final composition. The compositional perturbations are small in the examples considered here, and the two procedures provide nearly identical values for the offset associated with a given composition anomaly.

Unless otherwise stated, all calculations are carried out for a temperature of $25^{\circ} \mathrm{C}$ and a sea pressure of $0 \mathrm{dbar}$. This is appropriate for comparisons with laboratory measurements on water samples. The accuracy of the Pa08 conductivity model has also been most comprehensively investigated under these conditions.

\subsection{A composition model for standard seawater $\left(S_{\mathbf{P}}=35\right)$}

Typical oceanic concentrations of virtually all elements in the periodic table are now known (e.g., Nozaki, 1997), but many elements are present in only trace quantities. The model base state (labelled SSW76, see columns 1-2 of Table 3) is meant to match as closely as possible the composition of SSW derived from North Atlantic surface seawater circa 1976 used to determine both PSS-78 and the 1980 equation of state (Millero and Poisson, 1981). It includes all components that can affect salinity down to the level of $1 \mathrm{mg} \mathrm{kg}^{-1}$, although traditional practice in not including the dissolved gases $\mathrm{N}_{2}$ $\left(16 \mathrm{mg} \mathrm{kg}^{-1}\right)$, and $\mathrm{O}_{2}\left(0-8 \mathrm{mg} \mathrm{kg}^{-1}\right)$ is followed. This composition is denoted by a vector $C_{0}=\left\{c_{1} c_{2} \ldots c_{N_{c}}\right\}$, where $c_{i}$ is the concentration (mol kg-1 solution) of the $i$ th of $N_{c}$ constituents. SSW76 is defined to have $S_{\mathrm{P}}=35$ (exactly), and constructed to have a chlorinity $\mathrm{Cl}$ of $19.374 \mathrm{~g} \mathrm{~kg}^{-1}$ according to the definition (Millero et al., 2008) derived from titration procedures:

$$
C l /\left(\mathrm{g} \mathrm{kg}^{-1}\right) \equiv 0.3285234 \cdot M_{\mathrm{Ag}} \cdot\left(\left[\mathrm{Cl}^{-}\right]+\left[\mathrm{Br}^{-}\right]+\left[\mathrm{I}^{-}\right]\right)
$$

with [.] denoting concentrations and $M_{\mathrm{Ag}}=$ $107.8682 \mathrm{~g} \mathrm{~mol}^{-1}$ the molar mass of silver. In addition, the reference salinity $S_{\mathrm{R}} \equiv u_{\mathrm{PS}} S_{\mathrm{P}}$ (Millero et al., 2008), will be (exactly) $35.16504 \mathrm{~g} \mathrm{~kg}^{-1}$.

The recently defined reference composition of standard seawater (from Millero et al., 2008, hereafter M08) was taken as a starting point in specifying SSW76. However, M08 cannot easily be used directly as a model for seawater in this study for several reasons.

First, the fixed ratios of carbonate system components in M08 are not convenient for studying spatial and temporal variations in seawater composition. Although specification of the carbonate system in seawater requires (at minimum) 7 species (Millero, 1995), some of which appear in amounts much less than $1 \mathrm{mg} \mathrm{kg}^{-1}$, their concentrations are not independent. Rather, they are coupled by constants governing the chemical equilibria between them. Only two parameters from the set $\left\{\mathrm{TA}, \mathrm{pH}, f \mathrm{CO}_{2}\right.$, DIC $\}$ are required to fully specify the carbonate system (with minor corrections arising from borate and $\mathrm{SO}_{4}^{2-}$ concentrations). From these parameters, the equilibrium constants (denoted by $K_{w}, K_{0}, K_{1}, K_{2}, K_{B}$ and parameterized in Dickson et al., 2007) are used to compute the ionic concentrations.

It is desirable in the model to let the carbonate ions remain in chemical equilibrium in all conditions as this more closely models the behavior of real water. Thus instead of using the M08 ionic concentrations, the carbonate system is defined using two of the standard parameters. The first parameter used is Total Alkalinity (TA), set to $2300 \mu \mathrm{mol} \mathrm{kg}^{-1}$, where 
Table 3. The chemical compositions of model SSW76, NPIW, and their differences. For both water types we show concentrations in molar units and their contribution to mass-based salinities. The upper 9 species are conservative. Both SSW76 and NPIW have a chlorinity of $19374 \mathrm{mg} \mathrm{kg}^{-1}$, but chlorinity is not exactly the same as the concentration of $\mathrm{Cl}^{-}$(Millero et al., 2008). The next 7 species form the carbonate system, followed by the two nutrients. We also list other parameters that can be used to specify the equilibria involved in the carbonate system. $S_{\mathrm{A}}^{\mathrm{soln}}, \kappa, S_{\mathrm{P}}$, and $S_{\mathrm{R}}$ are computed according to the formulas discussed in the text. The charge differences in the rightmost column are indicated with two signs. The first represents the net change (increase or decrease), and the second whether these are positive or negative charges.

\begin{tabular}{|c|c|c|c|c|c|c|c|}
\hline \multirow[b]{2}{*}{ Species } & \multicolumn{2}{|c|}{ SSW76 } & \multicolumn{2}{|c|}{ NPIW } & \multicolumn{3}{|c|}{ NPIW-SSW76 } \\
\hline & $\mathrm{mmol} \mathrm{kg}^{-1}$ & $\mathrm{mg} \mathrm{kg}^{-1}$ & $\mathrm{mmol} \mathrm{kg}^{-1}$ & $\mathrm{mg} \mathrm{kg}^{-1}$ & $\mathrm{mmol} \mathrm{kg}^{-1}$ & $\mathrm{mg} \mathrm{kg}^{-1}$ & $\mu \mathrm{eq} \mathrm{kg}^{-1}$ \\
\hline $\mathrm{Na}^{+}$ & 468.96335 & 10781.35913 & 468.96335 & 10781.35913 & 0.00000 & 0.00000 & 0.00 \\
\hline $\mathrm{Mg}^{2+}$ & 52.81702 & 1283.71757 & 52.81702 & 1283.71757 & 0.00000 & 0.00000 & 0.00 \\
\hline $\mathrm{Ca}^{2+}$ & 10.28205 & 412.08380 & 10.37705 & 415.89129 & 0.09500 & 3.80748 & ++190.00 \\
\hline $\mathrm{K}^{+}$ & 10.20769 & 399.10324 & 10.20769 & 399.10324 & 0.00000 & 0.00000 & 0.00 \\
\hline $\mathrm{Sr}^{2+}$ & 0.09066 & 7.94332 & 0.09066 & 7.94332 & 0.00000 & 0.00000 & 0.00 \\
\hline $\mathrm{Cl}^{-}$ & 545.86954 & 19352.71293 & 545.86954 & 19352.71293 & 0.00000 & 0.00000 & 0.00 \\
\hline $\mathrm{SO}_{4}^{2-}$ & 28.23526 & 2712.35228 & 28.23526 & 2712.35228 & 0.00000 & 0.00000 & 0.00 \\
\hline $\mathrm{Br}^{-4}$ & 0.84208 & 67.28578 & 0.84208 & 67.28578 & 0.00000 & 0.00000 & 0.00 \\
\hline $\mathrm{F}^{-}$ & 0.06832 & 1.29805 & 0.06832 & 1.29805 & 0.00000 & 0.00000 & 0.00 \\
\hline $\mathrm{HCO}_{3}^{-}$ & 1.90028 & 115.94926 & 2.25090 & 137.34304 & 0.35062 & 21.39378 & +-350.62 \\
\hline $\mathrm{CO}_{3}^{2-}$ & 0.16285 & 9.77242 & 0.08222 & 4.93414 & -0.08063 & -4.83828 & --161.25 \\
\hline $\mathrm{B}(\mathrm{OH})_{3}$ & 0.34579 & 21.38143 & 0.38239 & 23.64422 & 0.03660 & 2.26279 & 0.00 \\
\hline $\mathrm{B}(\mathrm{OH})_{4}^{-}$ & 0.06923 & 5.45779 & 0.03263 & 2.57262 & -0.03660 & -2.88517 & --36.60 \\
\hline $\mathrm{CO}_{2}$ & 0.01687 & 0.74233 & 0.04687 & 2.06284 & 0.03001 & 1.32051 & 0.00 \\
\hline $\mathrm{OH}^{-}$ & 0.00480 & 0.08172 & 0.00205 & 0.03483 & -0.00276 & -0.04688 & --2.76 \\
\hline $\mathrm{H}^{+}$ & 0.00001 & 0.00001 & 0.00002 & 0.00002 & 0.00001 & 0.00001 & ++0.01 \\
\hline $\mathrm{NO}_{3}^{-}$ & 0.00000 & 0.00000 & 0.04000 & 2.48020 & 0.04000 & 2.48020 & +-40.00 \\
\hline $\mathrm{Si}(\mathrm{OH})_{4}$ & 0.00000 & 0.00000 & 0.17000 & 16.33953 & 0.17000 & 16.33953 & 0.00 \\
\hline TA & \multicolumn{2}{|c|}{$2300.0 \mu \mathrm{eq} \mathrm{kg}-1$} & \multicolumn{2}{|c|}{$2450.0 \mu \mathrm{eq} \mathrm{kg}^{-1}$} & \multicolumn{3}{|c|}{$150.0 \mu \mathrm{eq} \mathrm{kg}^{-1}$} \\
\hline DIC & \multicolumn{2}{|c|}{$2080.0 \mu \mathrm{mol} \mathrm{kg}-1$} & \multicolumn{2}{|c|}{$2380.0 \mu \mathrm{mol} \mathrm{kg}-1$} & \multicolumn{3}{|c|}{$300.0 \mu \mathrm{mol} \mathrm{kg}-1$} \\
\hline $\mathrm{pH}_{\mathrm{TOT}}$ & \multicolumn{2}{|c|}{7.89892} & \multicolumn{2}{|c|}{7.52859} & \multicolumn{3}{|c|}{-0.37033} \\
\hline$S_{\Lambda}^{\text {soln }}$ & \multicolumn{2}{|c|}{$35.17124 \mathrm{~g} \mathrm{~kg}^{-1}$} & \multicolumn{2}{|c|}{$35.21108 \mathrm{~g} \mathrm{~kg}^{-1}$} & \multicolumn{3}{|c|}{$\delta S_{*}^{\text {soln }}=0.03983 \mathrm{~g} \mathrm{~kg}^{-1}$} \\
\hline$\kappa^{\mathrm{A}}$ & \multicolumn{2}{|c|}{$53064.8 \mu \mathrm{S} \mathrm{cm}^{-1}$} & \multicolumn{2}{|c|}{$53073.1 \mu \mathrm{S} \mathrm{cm}^{-1}$} & \multicolumn{3}{|c|}{$\delta \kappa=8.324 \mu \mathrm{S} \mathrm{cm}^{-1}$} \\
\hline$S_{\mathrm{P}}$ & \multicolumn{2}{|c|}{35.00000} & \multicolumn{2}{|c|}{35.00618} & \multicolumn{3}{|c|}{$\delta S_{\mathrm{P}}=0.00618$} \\
\hline$S_{\mathrm{R}}$ & \multicolumn{2}{|c|}{35.16504} & \multicolumn{2}{|c|}{35.17125} & & & \\
\hline
\end{tabular}

$\mathrm{TA} \equiv\left[\mathrm{HCO}_{3}^{-}\right]+2\left[\mathrm{CO}_{3}^{2-}\right]+\left[\mathrm{B}(\mathrm{OH})_{4}^{-}\right]+\left[\mathrm{OH}^{-}\right]-\left[\mathrm{H}^{+}\right]$

A total borate component is specified by adding together the $\mathrm{B}(\mathrm{OH})_{4}^{-}$and $\mathrm{B}(\mathrm{OH})_{3}$ components of $\mathrm{M} 08$, and $\mathrm{SO}_{4}^{2-}$ concentrations (required for carbonate system calculations) are also taken from M08.

Second, although the TA of SSW76 and M08 are the same, the total dissolved inorganic carbon (DIC) defined as

$\mathrm{DIC} \equiv\left[\mathrm{CO}_{2}\right]+\left[\mathrm{HCO}_{3}^{-}\right]+\left[\mathrm{CO}_{3}^{2-}\right]$

in the two models is different (as are $\mathrm{pH}$ and $f \mathrm{CO}_{2}$ ). The reason for this is that attempts to match $\delta S_{\mathrm{A}}^{\text {soln }}$ observations, as well as weak independent evidence, suggest that the DIC content of SSW is somewhat higher than that specified in M08.

M08 specifies ionic composition after setting the fugacity $f \mathrm{CO}_{2}$ to $333 \mu$-atm at a temperature of $25^{\circ} \mathrm{C}$. This $f \mathrm{CO}_{2}$ is appropriate for an equilibrium with atmospheric levels when the measurements were made to define PSS-78, and at $25^{\circ} \mathrm{C}$ implies a DIC of $1963 \mu \mathrm{mol} \mathrm{kg}{ }^{-1}$. Typically, after sampling, $\mathrm{SSW}$ is filtered and sterilized for $\approx 30$ days at temperatures of $28^{\circ} \mathrm{C}$ before 1991 (batch numbers up to P115), but only 18 $21^{\circ} \mathrm{C}$ since then (P. Ridout, OSIL, personal communication, 2009). Since the solubility of $\mathrm{CO}_{2}$ is strongly dependent on temperature, the choice of temperature is important. At $20^{\circ} \mathrm{C}$ equilibrium levels of DIC would be around $2006 \mu \mathrm{mol} \mathrm{kg}-1$, 
and at $28^{\circ} \mathrm{C}$ they would be $1937 \mu \mathrm{mol} \mathrm{kg}{ }^{-1}$. The change in DIC due to increasing atmospheric $\mathrm{CO}_{2}$ levels is slightly smaller. At a temperature of $25^{\circ} \mathrm{C}$ and a present-day $f \mathrm{CO}_{2}$ of $380 \mu$-atm, calculated DIC would be $1992 \mu \mathrm{mol} \mathrm{kg}^{-1}$.

However, there are indications that measured DIC values in ampoules of SSW are often (but not always) somewhat higher than these predicted equilibriums at bottling time, and this is generally believed to be caused by the decomposition of residual organic matter after bottling. Unfortunately, although the TA of standard seawater has been studied (Goyet et al., 1985; Millero et al., 1993), there has been no systematic attempt to analyze the DIC content of standard seawater, and its temporal stability. Brewer and Bradshaw (1975) measured $2238 \mu \mathrm{mol} \mathrm{kg}{ }^{-1}$ in SSW batch P61. Recent (September 2009) measurements of DIC in ampoules of old SSW from batches P79 (from 1977), P111 (1989), and bottled P140 (2000) found values of 2610, 2200 , and $1803 \mu \mathrm{mol} \mathrm{kg}{ }^{-1}$, respectively. The spread between replicates from different ampoules of the same batch was $10-20 \mu \mathrm{mol} \mathrm{kg}{ }^{-1}$, larger than measurement uncertainty, but much smaller than the variations between batches.

In fact, as will be shown later, conductivity is not sensitive to variations in DIC, although $S_{\mathrm{A}}^{\text {soln }}$ (and hence $\delta S_{\mathrm{R}}^{\text {soln }}$ ) are greatly affected. A DIC change of $100 \mu \mathrm{mol} \mathrm{kg}{ }^{-1}$ is equivalent to an absolute salinity variation of $\approx 0.006 \mathrm{~g} \mathrm{~kg}^{-1}$, but will change $S_{\mathrm{P}}$ by only 0.0007 . Since a primary purpose of our $\delta S_{\mathrm{R}}^{\text {soln }}$ corrections is (eventually) to calculate densities, it may be more important to choose a model DIC value that will match that of the water used in the measurements defining the 1980 equation of state (Millero and Poisson, 1981), relating salinity and density. This is stated by Millero (2000) to have been $2226 \mu \mathrm{mol} \mathrm{kg}{ }^{-1}$. However, density fits to Pacific ocean data published in that paper also suggest zero density anomalies occur when DIC $=2000 \mu \mathrm{mol} \mathrm{kg}{ }^{-1}$.

Since ampoules of SSW are sealed, this large range of uncertainty is ultimately related to the effects of organic material and its neglect in the inorganic seawater chemistry model developed here. This makes it difficult to specify a useful model value for DIC in advance of any calculations, although both density measurements and direct observations suggest concentrations somewhat higher than that of M08. It is probably desirable that our definition (eventually) imply that $\delta S_{\mathrm{R}}^{\text {soln }} \approx 0$ for observations from the surface North Atlantic. Thus, after some tuning, DIC is set to $2080 \mu \mathrm{mol} \mathrm{kg}^{-1}$.

An inappropriate value for the DIC of SSW76 will (eventually) lead to a near-constant offset in all calculated absolute salinity variations. Although this offset is thus potentially significant, it will apply to all calculations and hence may have little effect on comparisons between different seawaters, or on any computation in which additions rather than absolute levels of DIC are specified.

The last difference is that non-conservative nutrient species must be included. Changes in $\mathrm{NO}_{3}^{-}$and $\mathrm{Si}(\mathrm{OH})_{4}$ will exceed $1 \mathrm{mg} \mathrm{kg}^{-1}$ in a seawater with $S_{\mathrm{R}} \approx 35 \mathrm{~g} \mathrm{~kg}^{-1}$ and are related to the salinity variations we seek to model (Brewer and Bradshaw, 1975; Millero, 2000). These nutrients are assumed to have a concentration of zero in SSW76.

Following customary practice the mass of $\mathrm{Na}^{+}$is adjusted slightly to maintain charge neutrality, once all other ionic components are specified in SSW76. This may partly account for the contributions of neglected ionic constituents, of which the most important are the conservative elements $\mathrm{Li}^{+}\left(0.18 \mathrm{mg} \mathrm{kg}^{-1}\right.$, Soffyn-Egli and Mackenzie, 1984), $\mathrm{Rb}^{+}$ $\left(0.12 \mathrm{mg} \mathrm{kg}^{-1}\right)$, and the nutrient $\mathrm{PO}_{4}^{-}\left(0-0.23 \mathrm{mg} \mathrm{kg}^{-1}\right)$.

The computed absolute salinity $s\left(C_{0}\right)$ is $35.171 \mathrm{~g} \mathrm{~kg}^{-1}$ for SSW76. This differs by $0.006 \mathrm{~g} \mathrm{~kg}^{-1}$ from the defined value of $S_{\mathrm{R}}$ for SSW of $35.16504 \mathrm{~g} \mathrm{~kg}^{-1}$. The mismatch is within the uncertainty of $\pm 0.007 \mathrm{~g} \mathrm{~kg}^{-1}$ suggested by Millero et al. (2008), although much of that error arises from uncertainty about the amount of $\mathrm{SO}_{4}^{2-}$. In contrast, the salinity difference here largely arises from differences in carbonate parameters. However, it should be emphasized that SSW76 is a model of seawater, and not necessarily a better (or worse) description of actual seawater than M08. This is because the assumed precision for some of the constituent concentrations is greater than that of the best observations.

Strictly speaking, the difference between $\gamma=35.171 / 35$ and $u_{\mathrm{PS}}$ means that the offsets computed in this paper are is not exactly those required to get the true absolute salinity. Instead they will be in error by a scale factor of $\gamma / u_{\mathrm{PS}} \approx 1.00017$. However, the difference is small enough that it is not of any practical importance and the difference will be ignored.

\subsection{A model for standard seawater $\left(S_{\mathbf{P}} \neq 35\right)$}

The composition of SSW $C_{*}$ at practical salinities other than 35 can be specified in different ways. The simplest is to multiply all constituent concentrations by a constant fraction (i.e.

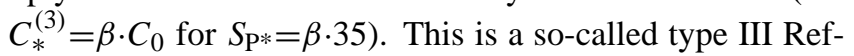
erence Seawater (Millero et al., 2008). However, during the specification of PSS-78, SSW was evaporated or diluted with distilled water in order to change its salinity, and again equilibrated with the atmosphere. This makes it more reasonable to specify a type II Reference Seawater $C_{*}^{(2)}$, where only the concentrations of conservative tracers, as well as TA, are multiplied by the constant fraction $\beta$ for $S_{\mathrm{P} *}=\beta \cdot 35$, but $f \mathrm{CO}_{2}$ is kept constant.

Assuming in advance of our later discussion that the conductivity model can predict the effects of perturbations reasonably well, and realizing that $C_{*}^{(2)}$ and $C_{*}^{(3)}$ are very similar, the differences in conductivity, absolute salinity, and conductivity-derived practical salinity arising from these two approximations can be estimated as:

$\delta \kappa^{\prime}=\kappa_{\mathrm{Pa} 08}\left(C_{*}^{(2)}\right)-\kappa_{\mathrm{Pa} 08}\left(C_{*}^{(3)}\right)$

$\delta S_{\mathrm{A}}^{\prime}=s\left(C_{*}^{(2)}\right)-s\left(C_{*}^{(3)}\right)$ 
$\delta S_{\mathrm{P}}^{\prime}=f_{78}\left(\kappa_{\mathrm{Pa} 08}\left(C_{*}^{(2)}\right)\right)-f_{78}\left(\kappa_{\mathrm{Pa} 08}\left(C_{*}^{(3)}\right)\right)$

where $\kappa_{\mathrm{Pa} 08}$ is the conductivity estimate computed using the $\mathrm{Pa} 08$ conductivity model and the two absolute salinities in Eq. (9) are calculated using Eq. (2).

Over the range of $5<S_{\mathrm{P}}<40$, the conductivity differences are $\delta \kappa^{\prime}< \pm 0.8 \mu \mathrm{S} \mathrm{cm}^{-1}$ (Fig. 1a), which in turn implies $\delta S_{\mathrm{P}}^{\prime}< \pm 0.0005$ (Fig. 1b). These uncertainties are negligible. However, the changes in absolute salinity $\delta S_{\mathrm{A}}^{\prime}$ are an order of magnitude larger, and can approach $0.004 \mathrm{~g} \mathrm{~kg}^{-1}$ at salinities of about 17 (Fig. 1b) although the differences are not important for typical seawater salinities near 35 .

\subsection{A perturbation model for observed seawater}

As a particular parcel of seawater is advected through the ocean, biogeochemical processes alter its composition so it differs from that of SSW. These perturbations are represented by a vector $\delta C_{*}$, so that the composition becomes $C_{*}+\delta C_{*}$. Biogeochemical processes will not alter the unreactive components of seawater, so these components of $\delta C_{*}$ are zero. Changes occur due to variations in non-conservative nutrients and components of the carbonate system. However, calculations appropriate for estuarine waters may also involve changes in some of the unreactive components as they may also be components of freshwaters.

Note that a slight simplification has been made. Actual additions of a particular species to a volume of water will (slightly) change the concentrations of all other species, when concentrations are measured per unit mass of solution (or per unit volume) as is done here. However, modeling this additional complication is not necessary here as we are not tracking individual parcels.

Nutrient changes that lie above our threshold of $1 \mathrm{mg} \mathrm{kg}^{-1}$ include nitrate $\left(\mathrm{NO}_{3}^{-}\right)$and silicate. The latter can appear in the form of $\mathrm{SiO}_{2}, \mathrm{Si}(\mathrm{OH})_{4}$, and $\mathrm{SiO}(\mathrm{OH})_{3}^{-}$. Typically in the $\mathrm{pH}$ range of seawater all but a few percent appears as nonconductive $\mathrm{Si}(\mathrm{OH})_{4}$, and it will therefore be assumed that only a negligible amount appears in the other forms.

Changes to the carbonate system can be determined by measurements of TA and DIC (or any two equivalent measurements, e.g. $\mathrm{pH}$ and TA). With the addition of $\mathrm{NO}_{3}^{-}$, and a change in TA, the number of positive and negative charges in the composition will probably no longer balance. Other processes must therefore be present in the real ocean to balance this excess (or rather, the change in TA arises to compensate for the effects of these other processes). The dissolution of $\mathrm{CaCO}_{3}$ is likely the predominant mechanism at work (Sarmiento and Gruber, 2006). The negative charges and carbon from $\mathrm{CO}_{3}^{2-}$ are already accounted for in the increase in TA and DIC respectively. An increase in $\mathrm{Ca}^{2+}$ is also known to occur in deep waters (de Villiers, 1998), and we assume that this will balance the change in total charge. That is, we
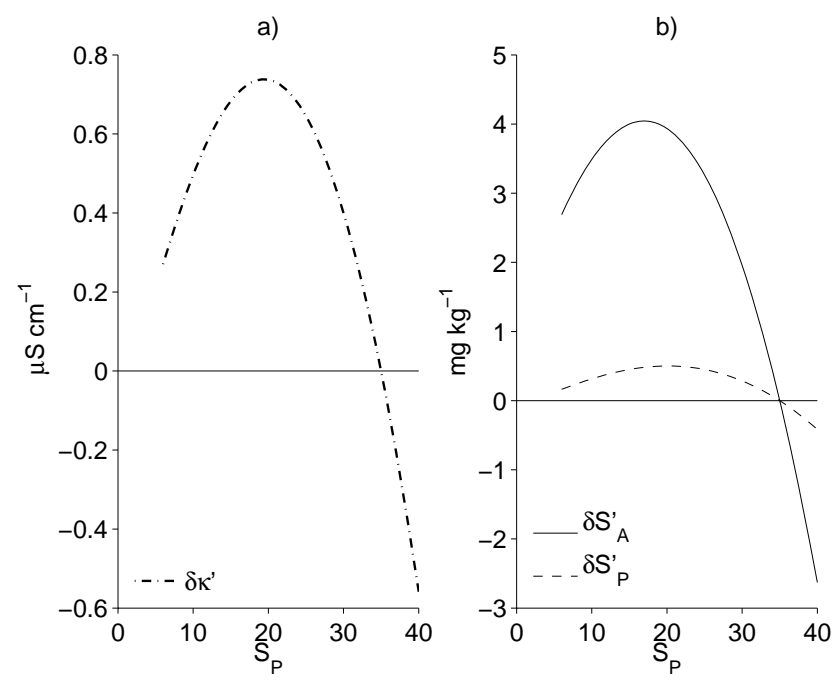

Fig. 1. Comparison between constant $f \mathrm{CO}_{2}$ and constant fraction models for dilution of seawater. (a) Difference in conductivities. (b) Differences in practical and absolute salinity.

assume a relationship between the increase in TA and the increase in concentrations of $\mathrm{Ca}^{2+}$ from dissolution and $\mathrm{NO}_{3}^{-}$ from remineralization:

$\Delta \mathrm{TA}=2 \Delta\left[\mathrm{Ca}^{2+}\right]-\Delta\left[\mathrm{NO}_{3}^{-}\right]$

where $\Delta$ denotes changes. Thus our perturbations must include measured concentrations of $\mathrm{NO}_{3}^{-}, \mathrm{Si}(\mathrm{OH})_{4}, \mathrm{TA}$, and DIC, as well as an inferred change in $\mathrm{Ca}^{2+}$ using Eq. (11). Carbonate parameters are then recomputed using the equilibrium constant formulas described by Dickson et al. (2007).

Of course, other processes also occur in the ocean. For example, TA also varies with changes in phosphate and organic substances, although these contributions will fall below our threshold of importance. A more important process might be sulfate reduction on continental shelves (Chen, 2002), which may be responsible for a large part of TA increases in some areas. In order to model this situation Eq. (11) would be modified to:

$\Delta \mathrm{TA}=2 \Delta\left[\mathrm{Ca}^{2+}\right]-2 \Delta\left[\mathrm{SO}_{4}^{2-}\right]-\Delta\left[\mathrm{NO}_{3}^{-}\right]$

but now an additional relationship (specifying, e.g., the importance of $\mathrm{CaCO}_{3}$ dissolution relative to $\mathrm{SO}_{4}^{2-}$ reduction) is needed to complete the model. Speculation on this relationship is beyond the scope of this paper.

There is also evidence for significant (relative to our threshold) variations in the concentrations of $\mathrm{Mg}^{2+}$ in the vicinity of hydrothermal vents (de Villiers and Nelson, 1999). Again, the wider importance of this process, and a means of parameterizing these variations, is at present unknown. 


\subsection{A model for seawater conductivity}

The Pa08 model estimate $\kappa_{\mathrm{Pa} 08}$ of the true electrical conductivity $\kappa$ of a dilute multi-component aqueous ionic solution like seawater is computed using an equation which can be written in a simplified form as (Pawlowicz, 2008)

$\kappa_{\mathrm{Pa} 08}(C)=\sum_{i=1}^{N_{c}} \bar{\lambda}_{i} c_{i}^{*} z_{i}$

The in-situ ionic equivalent conductivities $\bar{\lambda}_{i}=\lambda_{i}^{\circ} f_{i} \overline{\alpha_{i}}$ are the product of infinite dilution equivalent conductivities $\lambda_{i}^{\circ}$ for the different ions (set to zero for nonionic species), and two reduction factors: $f_{i}\left(I^{*}\right) \leq 1$, accounting for relaxation and electrophoresis effects, and $\overline{\alpha_{i}}\left(I^{*}, C\right) \leq 1$, accounting for ion association effects at finite ionic strength $I^{*}$. The stoichiometric ionic strength $I^{*}$ is

$I^{*}=\frac{1}{2} \sum_{i=1}^{N_{c}} z_{i}^{2} c_{i}^{*}$

The valence of charge on the $i$ th ion is $z_{i}$ and its stoichiometric concentration $c_{i}^{*}\left(\mathrm{~mol} \mathrm{~L}^{-1}\right)$. This is related to $c_{i}$ through a density equation (Millero and Poisson, 1981):

$c_{i}^{*}=\rho\left(S_{\mathrm{P}}\right) c_{i}$

where we incur an error of at most $1 \times 10^{-5}$ by ignoring the fact that the true density will change slightly with composition perturbations $\delta C_{*}$. As $I^{*} \rightarrow 0$ we have $f_{i} \rightarrow 1$ and $\overline{\alpha_{i}} \rightarrow 1$.

The relaxation/electrophoresis reduction parameter $f_{i}$ for species $i$ depends on the concentrations of other species $j \neq i$ only through their contribution to $I^{*}$. However, the ion association parameter $\overline{\alpha_{i}}$ depends critically on the concentrations and identities of all other ions (i.e. on the total set of $\left.c_{i}^{*}, i=1, \ldots, N_{c}\right)$, as it is a weighted sum of interactions with all other anions (cations) for a cation (anion). In order to account for this the internal model structure is somewhat more complicated than Eq. (13) suggests. Both the infinite dilution equivalent conductivities, and the in-situ ionic equivalent conductivities determined by $\mathrm{Pa} 08$ for SSW76, are listed in Table 2.

The conductivity model used is identical to that described in $\mathrm{Pa} 08$, with the addition of parameters for $\mathrm{B}(\mathrm{OH})_{4}^{-}$, derived from observations of Corti et al. (1980). All numerical parameters are based purely on basic chemical measurements in binary solutions, without reference to any measurements made in seawater (or any other natural water).

The accuracy of the computed conductivity $\kappa_{\mathrm{Pa} 08}$ depends on the accuracy of the measured ionic concentrations $c_{i}^{*}$, as well as on biases in the calculation of the reduction factors $f_{i}$ and $\overline{\alpha_{i}}$. At salinities $<4 \mathrm{~g} \mathrm{~kg}^{-1}$ the relative accuracy $\varepsilon=\left(\kappa_{\mathrm{Pa} 08}-\kappa\right) / \kappa$ of the model is typically limited to \pm 0.03 by the accuracy of the chemical analyses used to determine composition (unpublished results). Once this error is reduced, by, e.g., statistical averaging, the true error is less than 0.007 over a range of chemical compositions. For seawater with salinities of $0.1-1 \mathrm{~g} \mathrm{~kg}^{-1}$ we find an overestimate of only 0.002. However, at the higher salinities of concern here model biases dominate the error, with $\varepsilon$ smoothly varying from about -0.01 at a salinity of $4\left(\kappa \sim 8 \mathrm{mS} \mathrm{cm}^{-1}\right)$ to about -0.10 at a salinity of 35 or $\kappa \sim 50 \mathrm{mS} \mathrm{cm}^{-1}$ (Fig. 2b).

\subsection{Conductivity perturbations for non-standard seawaters}

A salinity underestimate of order $3 \mathrm{~g} \mathrm{~kg}^{-1}$ resulting from using $\kappa_{\mathrm{Pa} 08}$ in Eq. (1) directly will not allow us to directly investigate the small compositional variations in typical seawater that we have discussed above, which are several orders of magnitude smaller. However, not only is $|\varepsilon| \ll 1$, but it is relatively insensitive to changes in chemical composition. A comparison of measured and predicted conductivities for a variety of saline ocean and lake waters in the range of $20-50 \mathrm{mS} \mathrm{cm}^{-1}$ (Fig. 2b) shows that the resulting error is virtually identical for different compositions at the same conductivity. This is very different from results found when considering baseline predictions formed by taking $f_{i}=\overline{\alpha_{i}}=1$, or equivalently using infinite dilution equivalent conductivities for the different components, ignoring all interionic interactions (Fig. 2a). Not only are these baseline predictions greatly in excess of true conductivities (so that $\varepsilon=O(1)$ ), but the excess is highly sensitive to the composition. The baseline $\varepsilon$ for Mahoney Lake is almost double that for seawater at the same conductivity. The model is therefore accounting for relative chemical composition correctly, but with an overall bias that depends (weakly) on the salinity.

Thus for model predictions during which only small changes $\delta C_{*}$ in composition are made, we can take the $\kappa_{\mathrm{Pa} 08}$ error $\varepsilon \approx$ constant. $\varepsilon$ is estimated from

$\kappa\left(C_{*}\right)=\kappa_{\mathrm{Pa} 08}\left(C_{*}\right) \cdot(1+\varepsilon)^{-1}$

knowing that $\kappa\left(C_{*}\right)=f_{78}^{-1}\left(S_{\mathrm{P} *}\right)$ for SSW76. Since we assume

$\kappa\left(C_{*}+\delta C_{*}\right) \approx \kappa_{\mathrm{Pa} 08}\left(C_{*}+\delta C_{*}\right) \cdot(1+\varepsilon)^{-1}$

the change in conductivity $\delta \kappa$ related to small compositional changes is:

$$
\begin{aligned}
\delta \kappa & \equiv \kappa\left(C_{*}+\delta C_{*}\right)-\kappa\left(C_{*}\right) \\
& \approx\left(\kappa_{\mathrm{Pa} 08}\left(C_{*}+\delta C_{*}\right)-\kappa_{\mathrm{Pa} 08}\left(C_{*}\right)\right) \cdot(1+\varepsilon)^{-1} \\
& =\delta \kappa_{\mathrm{Pa} 08} \cdot(1+\varepsilon)^{-1}
\end{aligned}
$$

Thus it appears that we can use $\mathrm{Pa} 08$ to usefully predict conductivity perturbations.

We can confirm the relationship postulated in Eq. (18) for $\mathrm{Pa} 08$, which suggests that increments will be modeled to the same relative accuracy $\varepsilon$ as conductivities themselves, by directly comparing numerical estimates from the model of various derivatives and other parameters related to conductivity increments with observations made in seawater. 


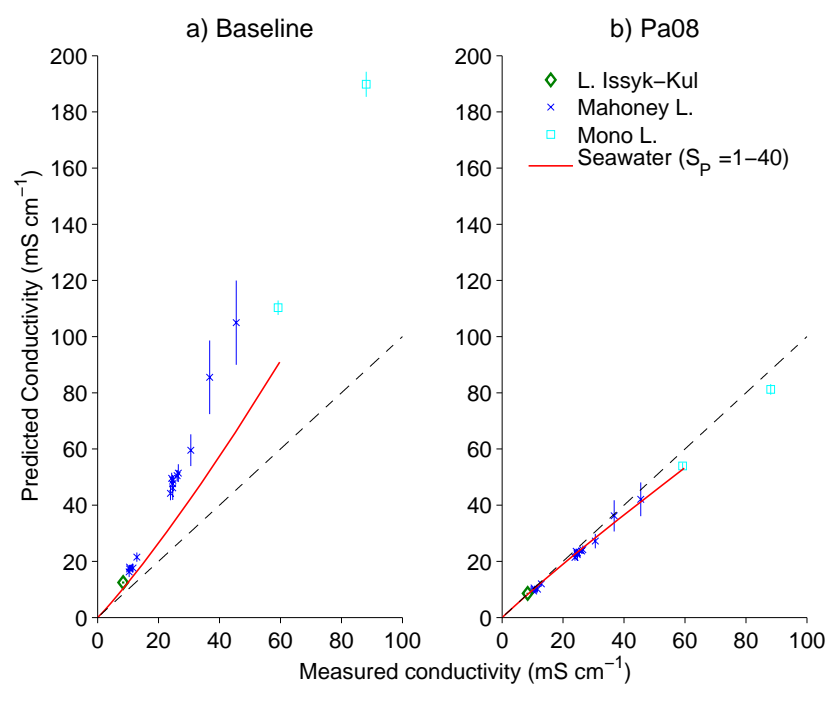

Fig. 2. Predicted versus measured $\kappa$ at $25^{\circ} \mathrm{C}$ for saline lakes Mahoney (Hall and Northcote, 1986), Mono (Jellison et al., 1999), and Issyk-Kul (Vollmer et al., 2002), as well as for seawater. (a) Baseline predictions without ionic interactions. (b) Pa08 predictions that include ionic interactions. Vertical bars show uncertainty based on the computed charge imbalance in the published chemical composition used for predictions. Lake Issyk-Kul is a warm deep lake with roughly equal amounts of $\mathrm{NaCl}$ and $\mathrm{MgSO}_{4}$, meromictic Mahoney Lake is dominated by $\mathrm{NaSO}_{4}$, Mono Lake contains a $\mathrm{Na}-\mathrm{CO}_{3}-\mathrm{Cl}-\mathrm{SO}_{4}$ brine and seawater is primarily composed of $\mathrm{NaCl}$.

First, direct estimates of the ionic equivalent conductivities $\lambda_{i}=\lambda_{i}^{\circ} f_{i}$ in seawater have been made using a radioactive tracer technique (Poisson et al., 1979). These parameters can also be extracted from the Pa08 model. When using the baseline (i.e. ignoring all modeled ionic interactions) the parameters are overpredicted with relative errors of 0.34 to 1.5 (Fig. 3a). However, when using the full Pa08 model, predictions are much closer to measured values, and the scatter is also greatly diminished. The mean relative error is -0.09 , almost identical to that found for conductivity itself.

Note that although the equivalent conductivities are generally underpredicted, the results for $\mathrm{SO}_{4}^{2-}$ show a slight overprediction. This ion associates strongly with most other cations. This makes it more difficult to model the equivalent conductivity of the ion, as pairing effects must be subtracted from measurements, but also tends to reduce the error when making predictions in actual solutions, as pairing effects are added back in.

More relevant results can be obtained by comparison with so-called partial equivalent conductivities $\bar{\Lambda}_{1 i}$, defined by

$\bar{\Lambda}_{1 i}=\left.\frac{\partial \kappa}{\partial E_{i}}\right|_{P, T, E_{j \neq i}, \ldots}$

These have been evaluated from laboratory measurements in which small changes in equivalent concentrations $E_{i}$ of the $i$ th of the $N_{s}$ salts (i.e. binary compounds) in seawater are
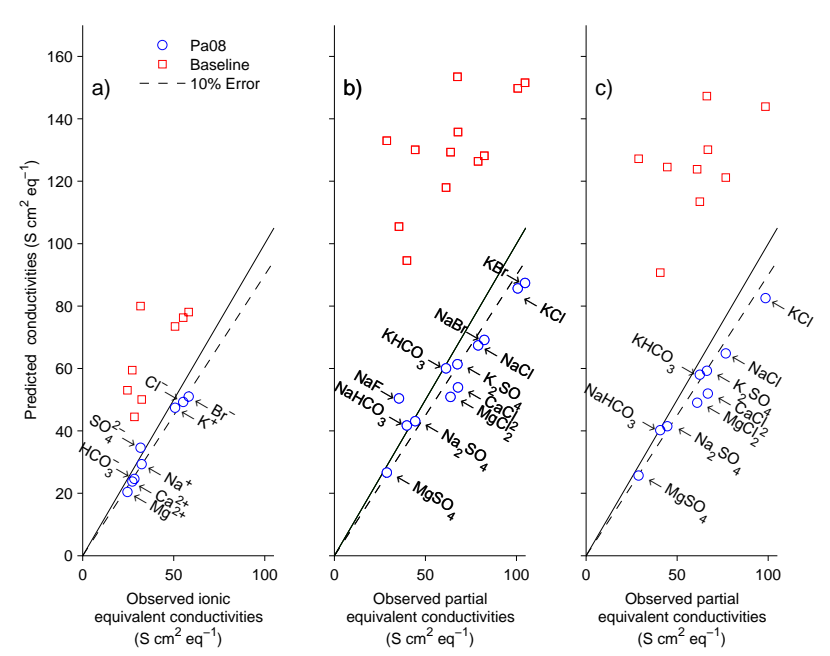

Fig. 3. Comparison between different $\mathrm{Pa} 08$ model-derived and measured parameters related to conductivity, for seawater. (a) Ionic equivalent conductivities in seawater of $S_{\mathrm{P}}=38.38$ at $25^{\circ} \mathrm{C}$. Original data from Poisson et al. (1979, Table 3). (b) Partial equivalent conductivities for various salts in seawater of $S_{\mathrm{P}}=35.13$ at $25^{\circ} \mathrm{C}$. Original data from Poisson et al. (1979, Table 4). (c) Partial equivalent conductivities for various salts in seawater of $S_{\mathrm{P}}=35.04$ at $23^{\circ} \mathrm{C}$. Original data from Conners and Weyl (1968, Table 4). Dashed line shows a relative error of -0.10 . Baseline predictions are made by ignoring all ionic interactions (i.e. using only infinite dilution equivalent conductivities). $\mathrm{Pa} 08$ results include relaxation/electrophoresis and ion pairing effects, with the former accounting for most of the reductions from baseline.

made by additions to a reference seawater (Park, 1964; Conners and Park, 1967; Conners and Weyl, 1968; Conners and Kester, 1974; Poisson et al., 1979). The data are corrected to show the derivatives when all other other conditions, and concentrations of all other ions, are held fixed. Note that the $\bar{\Lambda}_{1 i}$ are not equal to the sum of the corresponding equivalent conductivities for the anion and cation in Eq. (13) when evaluated at the ionic strength of seawater. Differences arise due to changes in the ionic strength, and in the effects of pairing (i.e., when $\bar{\alpha}<1$ ) between the components of the added salt and all other constituents in seawater. However, the $\bar{\Lambda}_{1 i}$ can easily be computed numerically from the Pa08 model.

For the salts studied, baseline predictions overestimate the partial equivalent conductivities by 0.46 to 3.4 (Fig. $3 \mathrm{~b}$ and c). When using the full $\mathrm{Pa} 08$ model, predictions are much closer to measured values, and the scatter is also greatly diminished (mean relative error -0.12 ). We also see that added salts containing $\mathrm{SO}_{4}^{2-}$ tend to lie close to the mean, showing that the inclusion of pairing effects does reduce possible problems associated with the ionic equivalent conductivity. In both cases the relative error of these variations is similar to that for conductivity itself. Thus the perturbation estimate Eq. (18) is apparently valid on both theoretical and observational grounds. 


\subsection{Salinities of non-standard seawaters}

The change in practical salinity resulting from a perturbation $\delta C_{*}$ added to an initial composition $C_{*}$ is given by

$$
\begin{aligned}
\delta S_{\mathrm{P}} & \equiv S_{\mathrm{P}}\left(C_{*}+\delta C_{*}\right)-S_{\mathrm{P}}\left(C_{*}\right) \\
& =f_{78}\left(\kappa\left(C_{*}+\delta C_{*}\right)\right)-f_{78}\left(\kappa\left(C_{*}\right)\right) \\
& \approx f_{78}\left(\kappa\left(C_{*}\right)+\delta \kappa_{\mathrm{Pa} 08} \cdot(1+\varepsilon)^{-1}\right)-f_{78}\left(\kappa\left(C_{*}\right)\right)
\end{aligned}
$$

where $\varepsilon$ and $\delta \kappa_{\mathrm{Pa} 08}$ are as defined in the previous section. At low salinities where $\kappa_{\mathrm{Pa} 08}$ has minimal bias the simpler approximation

$$
\delta S_{\mathrm{P}} \approx \delta S_{\mathrm{P}}^{*} \equiv f_{78}\left(\kappa_{\mathrm{Pa} 08}\left(C_{*}+\delta C_{*}\right)\right)-f_{78}\left(\kappa_{\mathrm{Pa} 08}\left(C_{*}\right)\right)
$$

provides an alternative method of estimating practical salinity changes which does not rely on assumptions about the magnitude of perturbations. In fact the function $f_{78}(\kappa)$ is smooth enough that the approximation holds to a degree of accuracy $\ll \varepsilon$ over all salinities (cf. Eq. 10), although we continue to use the computationally more intensive Eq. (22) unless otherwise specified. In addition to these changes in practical salinity, perturbations $\delta C *$ also lead to changes in absolute salinity according to:

$\delta S_{*}^{\text {soln }} \equiv s\left(C_{*}+\delta C *\right)-s\left(C_{*}\right)=s\left(\delta C_{*}\right)$

(by the linearity of Eq. 2).

If we consider a parcel of water with fixed chlorinity, additions $\delta C_{*}$ will therefore affect both the measured $S_{\mathrm{P}}$ and calculated absolute salinity. These changes will generally be different, giving rise to a salinity correction which can be estimated as:

$$
\begin{aligned}
\delta S_{\mathrm{R}}^{\mathrm{soln}(1)} & \equiv S_{\mathrm{A}}^{\mathrm{soln}}\left(C_{*}+\delta C_{*}\right)-\gamma S_{\mathrm{P}}\left(C_{*}+\delta C_{*}\right) \\
& =\delta S_{*}^{\text {soln }}-\gamma \delta S_{\mathrm{P}} \\
& \approx \delta S_{*}^{\text {soln }}-\delta S_{\mathrm{P}}
\end{aligned}
$$

This implies that $\delta S_{\mathrm{R}}^{\text {soln }}$ is approximately the change in absolute salinity, minus whatever compensating effects arise from conductivity. If a nonionic substance is added, $\delta S_{*}^{\text {soln }}$ will dominate the correction. On the other hand, adding very light but extremely conductive ions could lead to negative corrections arising mostly from changes in $S_{\mathrm{P}}$.

However, when converting ocean measurements to absolute salinity we are concerned with the corrections that arise when $S_{\mathrm{P}}$ is held constant, rather than those for fixed chlorinity. For non-standard seawater with a measured $S_{\mathrm{P}}$ we begin with a composition $C_{\mathrm{R}}$ appropriate for $\mathrm{SSW}$ of the same $S_{\mathrm{P}}$. However, the actual composition is $\beta C_{\mathrm{R}}+\delta C_{*}$. That is, the addition of other solids that dissociate into ions which increase conductivity must be matched by a slight dilution of our initial standard seawater composition in order to keep conductivity constant. The dilution factor $\beta$ for the SSW composition can be found by solving

$\kappa\left(\beta C_{\mathrm{R}}+\delta C_{*}\right)=\kappa\left(C_{\mathrm{R}}\right)$ which can be done iteratively, using $\kappa_{\mathrm{Pa} 08}$ in place of $\kappa$ on both sides of the equation. Then from Eqs. (4) and (28) the true correction is:

$$
\begin{aligned}
\delta S_{\mathrm{R}}^{\mathrm{soln}(2)} & =s\left(\beta C_{\mathrm{R}}+\delta C *\right)-s\left(C_{\mathrm{R}}\right) \\
& =\delta S_{*}^{\text {soln }}-(1-\beta) s\left(C_{\mathrm{R}}\right)
\end{aligned}
$$

Typically $\beta$ is very close to 1 and $\delta S_{\mathrm{R}}^{\text {soln(1) }}$ is within a few percent of $\delta S_{\mathrm{R}}^{\mathrm{soln}(2)}$ for the small perturbations of concern here. Although the latter is technically more correct for dealing with ocean data, the advantage of the former is that we can separately estimate effects of changing mass and changing number of electrical charges. We use the notation $\delta S_{\mathrm{R}}^{\text {soln }}$ when the distinction is unimportant.

\section{Results}

To illustrate the effects of compositional changes $\delta C_{*}$ first consider an extreme, but realistic, scenario. Investigations of the relationship between salinity and density suggest that largest salinity anomalies (of order $0.03 \mathrm{~g} \mathrm{~kg}^{-1}$ ) occur in the intermediate North Pacific (McDougall et al., 2009). This water represents the endpoint of the subsurface branch of the thermohaline circulation and thus provides an appropriate extreme. For comparative purposes model "North Pacific Intermediate Water" (NPIW) is normalized to have the same chlorinity as SSW76, although actual chlorinities in the North Pacific are about $0.3 \mathrm{~g} \mathrm{~kg}^{-1}$ lower. Based on typical observations, take this water to contain $\mathrm{Si}(\mathrm{OH})_{4}=170 \mu \mathrm{mol} \mathrm{kg}{ }^{-1}$ and $\mathrm{NO}_{3}^{-}=40 \mu \mathrm{mol} \mathrm{kg}{ }^{-1}$, with TA and DIC larger than in SSW76 by values of $150 \mu \mathrm{eq} \mathrm{kg} \mathrm{g}^{-1}$ and $300 \mu \mathrm{mol} \mathrm{kg}{ }^{-1}$ respectively. Columns 4-5 of Table 3 then contain the model composition $C_{0}+\delta C_{*}$ representing NPIW, with the perturbation $\delta C_{*}$ in columns 6-8.

Carbonate equilibria are recalculated from the new TA and DIC. $\mathrm{pH}$ on the Total scale drops to about 7.5 (again, all calculations are at $25^{\circ} \mathrm{C}$ ). The increases we specify actually cause concentrations of $\mathrm{CO}_{3}^{2-}$ and $\mathrm{B}(\mathrm{OH})_{4}^{-}$to decrease significantly. In addition, charge balance considerations require that the concentration of $\mathrm{Ca}^{2+}$ increase by $0.095 \mathrm{mmol} \mathrm{kg}{ }^{-1}$ or a little less than $1 \%$ over its value in SSW76. Measured increases in $\mathrm{Ca}^{2+}$ at depth in the North Pacific are of this order (de Villiers, 1998).

Applying the model directly (i.e. under conditions of fixed chlorinity) $\delta S_{\mathrm{P}} \approx 0.0062$ and $\delta S_{*}^{\text {soln }} \approx 0.0398 \mathrm{~g} \mathrm{~kg}^{-1}$, and

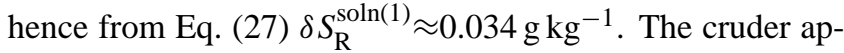
proximation $\delta S_{\mathrm{P}}^{*} \approx 0.0054$ underestimates $\delta S_{\mathrm{R}}^{\text {soln }}$ with a relative error of only -0.12 . A similar calculation, i.e., one with the same changes in TA, DIC, $\mathrm{NO}_{3}^{-}$, and $\mathrm{Si}(\mathrm{OH})_{4}$, under conditions of fixed conductivity, results in a dilution factor of $\beta=0.9998105$, and from Eq. (29) $\delta S_{\mathrm{R}}^{\mathrm{soln}(2)} \approx 0.033 \mathrm{~g} \mathrm{~kg}^{-1}$.

The two calculations result in almost exactly the same answer. From Eq. (27) we can consider the correction as the difference between changes in absolute and practical 
salinity. The $\mathrm{Si}(\mathrm{OH})_{4}$ component alone contributes about $0.016 \mathrm{~g} \mathrm{~kg}^{-1}$ to $\delta S_{\mathrm{R}}^{\text {soln }}$, or almost half of the correction. Much of the remainder arises primarily due to increases in $\mathrm{HCO}_{3}^{-}$, but there are both increases and decreases in other constituents. In fact, the changes in absolute salinity due to the increase in carbonates outweigh those due to the increase in $\mathrm{Si}(\mathrm{OH})_{4}$, but some of this carbonate ion increase is compensated by an increase in $S_{\mathrm{P}}$.

In order to better understand these values we investigate the conductivity. Model calculated ionic equivalent conductivities $\bar{\lambda}_{i}$ within our seawater are all significantly smaller than the infinite dilution equivalent conductivities $\lambda_{i}^{\circ}$ (columns 3 and 4 of Table 2), but with the exception of $\mathrm{H}^{+}$ and $\mathrm{OH}^{-}$are all of order $30 \mathrm{mS} \mathrm{cm}^{-1}\left(\mathrm{~mol} \mathrm{~L}^{-1}\right)^{-1}$. Very roughly then, conductivity changes will be proportional to changes in the number of charge pairs present. There are large changes in the concentrations of individual negative ions (last column of Table 3), but overall the increases and decreases in negative ions tend to balance out, matching (in total) the smaller increase in positive charges from $\mathrm{Ca}^{2+}$ produced by $\mathrm{CaCO}_{3}$ dissolution. Thus changes in absolute salinity are most strongly influenced by changes in $\mathrm{Si}(\mathrm{OH})_{4}$ and DIC, but changes in practical salinity occur mostly due to $\mathrm{CaCO}_{3}$ dissolution.

Further insight can be obtained by deriving an approximate relationship between $\delta S_{\mathrm{R}}^{\text {soln }}$ and $\delta C_{*}$. Seawater conductivity per unit mass of salt at $25^{\circ} \mathrm{C}$ in the model is $\bar{\psi}=\kappa_{\mathrm{Pa} 08} / S_{\mathrm{A}}^{\mathrm{soln}} \approx 1.35 \mathrm{mS} \mathrm{cm}^{-1}\left(\mathrm{~g} \mathrm{~kg}^{-1}\right)^{-1}$. Combining Eqs. (2), (4), and (13) and defining $\psi_{i}=\bar{\lambda}_{i} z_{i} \rho / M_{i}$ as the conductivity per unit mass of the $i$ th component:

$\delta S_{\mathrm{R}}^{\mathrm{soln}} \approx \sum_{i} M_{i}\left(1-\frac{\psi_{i}}{\bar{\psi}}\right) \delta c_{i}$

with numerical values appropriate for $S_{\mathrm{P}}=35$ given in Table 2. This expression illustrates the way in which the contribution of individual ions to $\delta S_{\mathrm{R}}^{\text {soln }}$ depends on the degree by which conductivity per unit mass $\psi_{i}$ differs from the average $\bar{\psi}$. The relationship is only approximate because the $\psi$ are not in fact constant, but will also vary with $\delta C_{*}$. In using this formula it is also important to recall that only charge balanced perturbations are meaningful, so that any scenario must involve changes in at least one cation and anion.

Examination of the mass effect coefficients $\left(1-\psi_{i} / \bar{\psi}\right)$ for different ions (listed in column 6 of Table 2) shows concentration perturbations in some ions (e.g., $\mathrm{Na}^{+}, \mathrm{Ca}^{2+}, \mathrm{Mg}^{2+}$, $\mathrm{K}^{+}, \mathrm{Cl}^{-}, \mathrm{F}^{-}$) result in little change to $\delta S_{\mathrm{R}}^{\text {soln }}$. These ions contribute to conductivity in an "average" way, with $\psi_{i} \approx \bar{\psi}$. Contrariwise, concentration changes in other ions do not affect conductivity in an average way and hence must be accounted for with a non-zero $\delta S_{\mathrm{R}}^{\text {soln }}$. Some of these (e.g., $\mathrm{Sr}^{2+}$, $\mathrm{Br}^{-}$) vary with the other conservative ions and hence will not appear in realistic perturbations that arise from biogeochemical processes. Nonconductive species contribute exactly their added mass. Several ions $\left(\mathrm{H}^{+}, \mathrm{OH}^{-}\right)$have an extremely large effect on conductivity, relative to their mass. However, the actual in-situ mass changes in these ions are so small that the overall effect on conductivity is minimal.

Sea salt is composed primarily of $\mathrm{Na}^{+}$and $\mathrm{Cl}^{-}$ions (Table 3). These contribute to conductivity in an average way, and so if there are small perturbations in their mass practical salinity changes will approximately account for the absolute salinity change. However, when using the full model, and ignoring nonconductive $\mathrm{Si}(\mathrm{OH})_{4}$, the change in absolute salinity $\delta S_{*}^{\text {soln }}$ is $\approx 0.024$, about 4 times larger than $\delta S_{\mathrm{P}}$. The salinity perturbation for modeling NPIW is composed largely of $\mathrm{HCO}_{3}^{-}$, for which $\psi_{i}$ is significantly different than $\bar{\psi}$. Using Eq. (30) we expect that an $\mathrm{HCO}_{3}^{-}$perturbation will give rise to a conductivity change that (when converted to salinity using the average factor $\bar{\psi}$ ) will only account for $\approx 0.3$ of the actual salinity change. The dominance of $\mathrm{HCO}_{3}^{-}$changes in $\delta C_{*}$, and their relatively unconductive nature, explains the insensitivity of predicted conductivity to variations in our assumptions about how seawater dilution should be modeled (cf. Sect. 2.2).

The choice between Eqs. (11) and (12) to balance TA changes will also have some consequences. An addition of $\mathrm{Ca}^{2+}$ will result in a compensating increase in conductivity, not affecting $\delta S_{\mathrm{R}}^{\text {soln }}$, but an equal decrease of $\mathrm{SO}_{4}^{2-}$ (which has an equivalent effect on TA) will not result in a fully compensating decrease in conductivity and hence will result in a smaller $\delta S_{\mathrm{R}}^{\text {soln }}$. For a concentration change of order $100 \mu \mathrm{mol} \mathrm{kg}^{-1}$ (i.e. for NPIW) the difference in $\delta S_{\mathrm{R}}^{\text {soln }}$ computed using the different scenarios is $0.005 \mathrm{~g} \mathrm{~kg}^{-1}$ using Eq. (30) or $0.008 \mathrm{~g} \mathrm{~kg}^{-1}$ using the full model. Since we do not have a good knowledge of the actual $\delta c_{i}$ for all constituents of seawater, we must rely on assumptions about biogeochemical processes to parameterize them. However, our prediction accuracy is then limited by the extent of our knowledge about these processes.

By considering only those ions both important in typical biogeochemical perturbations (i.e. large values in column 7 of Table 3) and with strong effect on $\delta S_{\mathrm{R}}^{\text {soln }}$ (i.e., with large values in the last column of Table 2), Eq. (30) can be further simplified. Only $\mathrm{HCO}^{-}, \mathrm{CO}_{3}^{2-}, \mathrm{CO}_{2}, \mathrm{~B}(\mathrm{OH})_{3}, \mathrm{~B}(\mathrm{OH})_{4}^{-}$, $\mathrm{NO}_{3}^{-}$and $\mathrm{Si}(\mathrm{OH})_{4}$ will have significant effects on $\delta S_{\mathrm{R}}^{\text {soln }}$. Since all of the carbonate parameters are related, and relationships such as Eq. (11) mean that the $\mathrm{NO}_{3}^{-}$term is not really independent either, a more sophisticated understanding of the carbonate system may allow a formula for $\delta S_{\mathrm{R}}^{\text {soln }}$ to be written more simply in terms of more general parameters such as TA and DIC.

However, for accurate calculations the full model is required. Unfortunately, although our model can be used to directly compute $\delta S_{\mathrm{R}}^{\text {soln }}$ in any situation, the computational process by which these values are derived is complex and relatively opaque. Previous workers have fitted simple empirical relationships to measurements, and these appear to be sufficient for practical purposes. Such formulas can also 

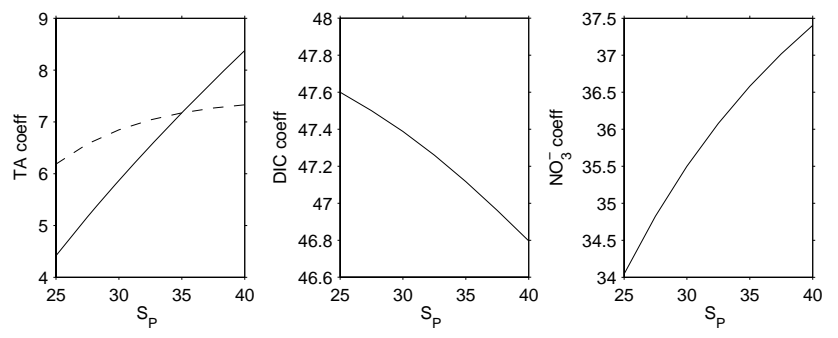

Fig. 4. Coefficients of the best fit equation $\delta S_{\mathrm{R}}^{\text {soln }}=a \mathrm{TA}+b \mathrm{DIC}+$ $c\left[\mathrm{NO}_{3}^{-}\right]$to model predictions, as a function of salinity. (a) Coefficient $a$. Dashed line shows a best fit curve as a function $T A \cdot S_{\mathrm{P}} / 35$ rather than TA. (b) Coefficient $b$. (c) Coefficient $c$.

be fitted to "measurements" calculated by the perturbation model. This is a simpler way to derive more straightforward formulas.

First consider perturbations when $S_{\mathrm{P}}=35$. The model is used to calculate $\delta S_{\mathrm{R}}^{\mathrm{soln}(2)}$ over a grid of $\delta C_{*}$ points within a range of $0 \leq \Delta \mathrm{TA} \leq 0.3 \mathrm{mmol} \mathrm{kg}^{-1}, 0 \leq \Delta \mathrm{DIC} \leq$ $0.3 \mathrm{mmol} \mathrm{kg}^{-1}$, and $0 \leq \Delta \mathrm{NO}_{3}^{-} \leq 0.040 \mathrm{mmol} \mathrm{kg}^{-1}$, with $\mathrm{Ca}^{2+}$ again varying according to Eq. (11). Inspection of the results shows that $\delta S_{\mathrm{R}}^{\text {soln(2) }}$ varies quasi-linearly with the components of the perturbation, and by least-squares fitting the equation

$$
\begin{gathered}
\delta S_{\mathrm{R}}^{\text {soln }} /\left(\mathrm{mgkg}^{-1}\right)=(47.11 \Delta \mathrm{DIC}+7.17 \Delta \mathrm{TA} \\
\left.+36.57 \Delta\left[\mathrm{NO}_{3}^{-}\right]\right) /\left(\mathrm{mmolkg}^{-1}\right)
\end{gathered}
$$

agrees very well with the full calculations, with a misfit standard error of $\pm 0.07 \mathrm{mg} \mathrm{kg}^{-1}$ and a maximum misfit of $0.3 \mathrm{mg} \mathrm{kg}^{-1}$.

The DIC coefficient is similar to the theoretical coefficient for $\mathrm{HCO}_{3}^{-}$(column 7 Table 2), and both the theoretical and fitted $\mathrm{NO}_{3}^{-}$coefficients are roughly comparable. The $\approx 20 \%$ difference results from both the biogeochemical relationships, as well as variations in the interionic interactions involved in conductivity.

Repeating the above procedure for $25 \leq S_{\mathrm{P}} \leq 40$, we find that the coefficients in the fit for $\delta S_{\mathrm{R}}^{\text {soln }}$ vary with salinity (Fig. 4). The coefficients for $\triangle \mathrm{DIC}$ and $\mathrm{NO}_{3}^{-}$vary only weakly (with a change of $<10 \%$ over the salinity range chosen) and in practical terms the variation can be ignored. However, the coefficient for $\triangle \mathrm{TA}$ varies strongly $(>50 \%$ change over the salinity range chosen), and almost linearly with $S_{\mathrm{P}}$. This suggests that Eq. (31) should be modified for situations when $S_{\mathrm{P}} \neq 35$ by replacing $\Delta \mathrm{TA}$ with $\Delta \mathrm{TA} \cdot S_{\mathrm{P}} / 35$. Note that the $\Delta$ signifies the change from SSW values at the specified salinity, e.g. the difference between observed TA and $2.300 \cdot S_{\mathrm{P}} / 35 \mathrm{mmol} \mathrm{kg}-1$. We also add in the total mass of $\mathrm{Si}(\mathrm{OH})_{4}$ to produce this final prediction formula:

$$
\begin{aligned}
& \delta S_{\mathrm{R}}^{\text {soln }} /\left(\mathrm{mgkg}^{-1}\right)=\left(47.11 \Delta \mathrm{DIC}+7.17\left(S_{\mathrm{P}} / 35\right) \Delta \mathrm{TA}\right. \\
& \left.\quad+36.57 \Delta\left[\mathrm{NO}_{3}^{-}\right]+96.11 \Delta\left[\mathrm{Si}(\mathrm{OH})_{4}\right]\right) /\left(\mathrm{mmolkg}^{-1}\right)
\end{aligned}
$$
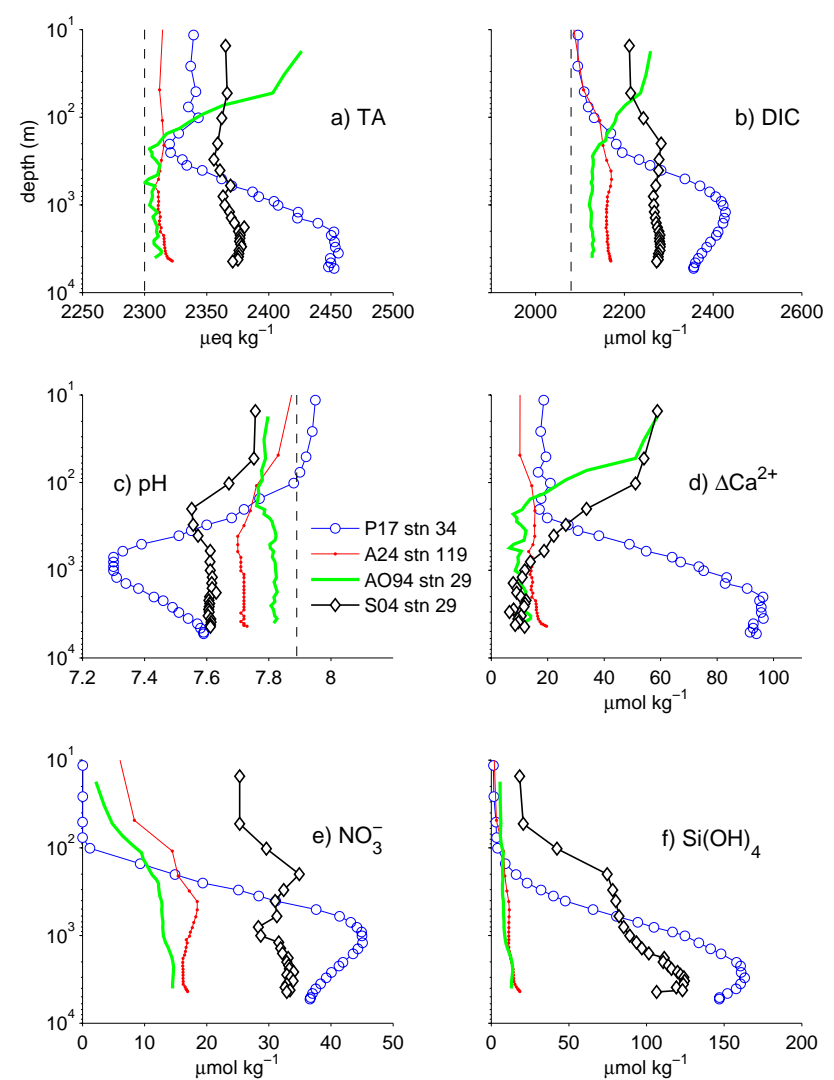

Fig. 5. Composition perturbations for example stations: North $\mathrm{Pa}-$ cific (WOCE line P17, station $34,37.5^{\circ} \mathrm{N}, 135.0^{\circ} \mathrm{W}, 10$ August 2001), North Atlantic (WOCE line A24, station 119, $52.73^{\circ} \mathrm{N}$, $34.71^{\circ} \mathrm{W}, 22$ June 1997) Arctic (AO94 station 29, 87.16 ${ }^{\circ} \mathrm{N}$, $160.71^{\circ}$ E, 17 August 1994) and Southern Ocean (WOCE line S04, station $29,62.02^{\circ} \mathrm{S}, 134.18^{\circ} \mathrm{E}, 9$ January 1995 ). (a) TA for all profiles. (b) DIC. (c) $\mathrm{pH}$ on the Total scale. (d) Computed change $\Delta \mathrm{Ca}^{2+}$ (e) $\mathrm{NO}_{3}^{-}$. (f) $\mathrm{Si}(\mathrm{OH})_{4}$. Vertical dashed lines show values in SSW76.

Note that there may be no easy way to empirically verify the different coefficients with ocean measurements. An empirical fit to data has resulted in the following relationship

$$
\begin{aligned}
& \delta S_{\mathrm{R}}^{\text {dens }} /\left(\mathrm{mgkg}^{-1}\right)=\left(50.13(\Delta \mathrm{TA}-0.032)+63.10 \Delta\left[\mathrm{NO}_{3}^{-}\right]\right. \\
& \left.\quad+96.30 \Delta\left[\mathrm{Si}(\mathrm{OH})_{4}\right]\right) /\left(\mathrm{mmolkg}^{-1}\right)
\end{aligned}
$$

(Millero, 2000, Eq. (3), rewritten to match the base value for $\triangle \mathrm{TA}$ used here and using a conversion factor of 756 between density and salinity changes as in that paper) which has a similar coefficient for $\mathrm{Si}(\mathrm{OH})_{4}$, but otherwise is numerically somewhat different. However, the different constituents included are strongly correlated in the ocean. A least-squares fit to a restricted set of actual observations may therefore be rather insensitive in certain directions of the parameter space of coefficients. Thus it is most appropriate at this stage to compare these different formulas only by examining their effect on measured ocean profiles. 

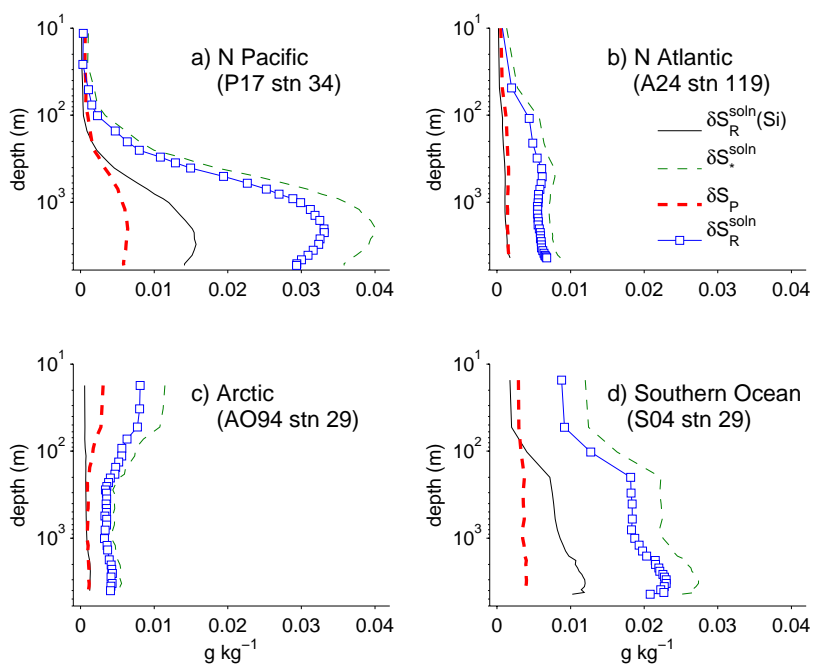

Fig. 6. Predicted corrections for measured water column profiles. Shown are the total fixed-conductivity correction $\delta S_{\mathrm{R}}^{\operatorname{soln}(2)}$, as well as the components of the fixed-chlorinity correction $\delta S_{\mathrm{R}}^{\text {soln }(1)}=\delta S_{*}^{\text {soln }}-\delta S_{\mathrm{P}}$ (with $\delta S_{\mathrm{R}}^{\mathrm{soln}(2)} \approx \delta S_{\mathrm{R}}^{\text {soln }(1)}$ ), and the component of the correction due to silicate alone, $\delta S_{\mathrm{R}}^{\mathrm{soln}}(\mathrm{Si})$. (a) N. Pacific profile. (b) N. Atlantic profile. (c) Arctic profile. (d) Southern Ocean profile.

The full calculation procedure can easily be applied to actual ocean profiles, as long as they include observations of $S_{\mathrm{P}}, \mathrm{TA}, \mathrm{DIC}, \mathrm{Si}(\mathrm{OH})_{4}$ and $\mathrm{NO}_{3}^{-}$. These parameters are now considered to be standard for deep-ocean hydrographic observations so no modification is needed in routine procedures. The latter 4 are enough to specify the nonconservative elements, with changes in $\mathrm{Ca}^{2+}$ inferred from Eq. (11) to maintain charge neutrality.

As an example, consider several recent high-quality hydrographic profiles from the North Atlantic, Arctic, and North Pacific, and Southern Ocean (Figs. 5-7). Previous $\delta S_{\mathrm{R}}^{\text {dens }}$ estimates have been made in all regions except the Arctic.

Surface nutrients are low in all profiles except in the Southern Ocean, and surface $\mathrm{pH}$ relatively high, although lower than in SSW (Fig. 5). The Arctic profile has a high surface TA, which implies higher $\mathrm{Ca}^{2+}$, and DIC, due to cold temperatures. Nutrients, TA, and DIC at depth are much higher in the North Pacific than in the other profiles. However, deep $\mathrm{pH}$ is much lower. Deep nutrient levels are typically higher than surface nutrients in all cases. Inferred $\Delta \mathrm{Ca}^{2+}$ is high in the Arctic and Southern Ocean, and high in the deep North Pacific.

The computed salinity correction $\delta S_{\mathrm{R}}^{\text {soln(2) }}$ is close to zero in the surface waters of the N. Pacific (Fig. 6a) and N. Atlantic (Fig. 6b), but is almost 0.008 in the surface waters of the Arctic (Fig. 6c). On the other hand, the correction is lowest at depth in the Arctic (only 0.003), but is as high as 0.033 in the deep North Pacific. The surface correction is highest
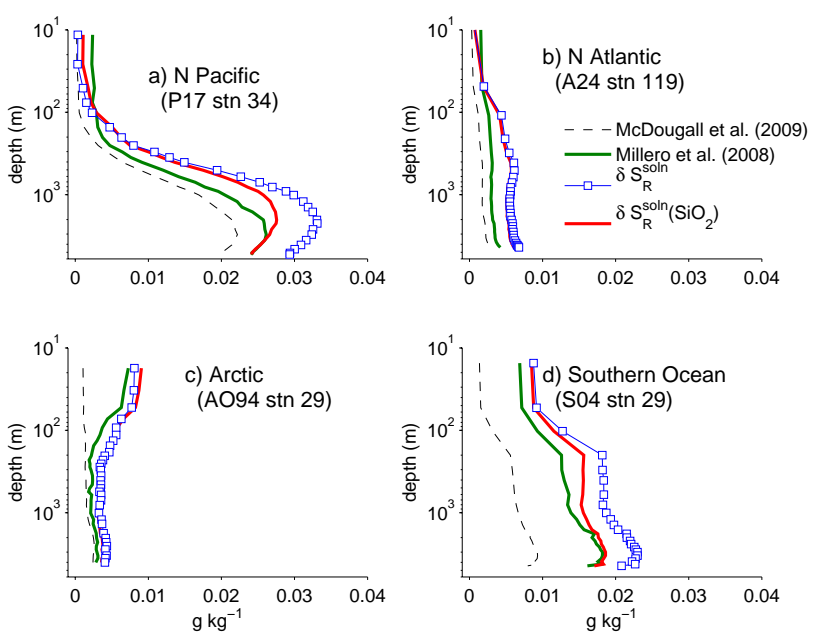

Fig. 7. Comparison between $\delta S_{\mathrm{R}}^{\operatorname{soln}(2)}$ computed with the full conductivity model in this paper with the results of empirical formulas for $\delta S_{\mathrm{R}}^{\text {dens }}$ provided by Millero et al. (2008) and McDougall et al. (2009). The latter provides corrections as a function of ocean basin, latitude, and measured $\mathrm{Si}(\mathrm{OH})_{4}$. Also shown are calculations using a reduced mass for added Si. (a) North Pacific. (b) North Atlantic. (c) Arctic. (d) Southern Ocean.

in the Southern Ocean. The correction itself is dominated by the $\delta S_{*}^{\text {soln }}$ in all cases with $\delta S_{\mathrm{R}}^{\text {soln(2) }} \approx 0.8 \delta S_{*}^{\text {soln }}$. The increase in ionic content does result in a small change in conductivity which partially compensates for the compositional change, but as before $\delta S_{\mathrm{P}} \ll \delta S_{*}^{\text {soln }}$.

Comparison of calculated $\delta S_{\mathrm{R}}^{\text {soln(2) }}$ with $\delta S_{\mathrm{R}}^{\text {dens }}$ produced by Eq. (33) and McDougall et al. (2009) for these stations are relatively good (Fig. 7). The general shape of depth profiles and overall magnitudes are similar, although our estimates appear to be systematically slightly larger. Correction factors in the deep Pacific and shallow Arctic are large, but are small in both Pacific and Atlantic surface waters, and deep Arctic waters. Our corrections are about 0.005 larger in the deep Pacific and not very different when $\delta S_{\mathrm{R}}^{\mathrm{soln}(2)} \approx 0$. Widest disagreement between the three estimates occurs in the Southern Ocean. For all profiles, the model $\delta S_{\mathrm{R}}^{\mathrm{soln}(2)}$ is the largest of the 3 estimates, and the predictions of McDougall et al. (2009) the smallest.

As a final comparison, the model is used to replicate the measurements in a controlled situation where the chemistry is more precisely known. Millero (1984) measured $\delta S_{\mathrm{R}}^{\text {dens }}$ (Fig. 8) for various mixtures composed of a known fraction $a$ of SSW and an artificial river water of known composition $C_{\mathrm{RW}}$ (Table 4):

$C_{\text {mixture }}=a C_{0}+(1-a) C_{\mathrm{RW}}$

with $0 \leq a \leq 1$. Here we take the dilution $C_{*}=a C_{0}$ as a base state (the difference between $C^{(2)}$ and $C^{(3)}$ dilutions does not materially affect the results here), and $\delta C_{*}=(1-a) C_{\mathrm{RW}}$ as a 


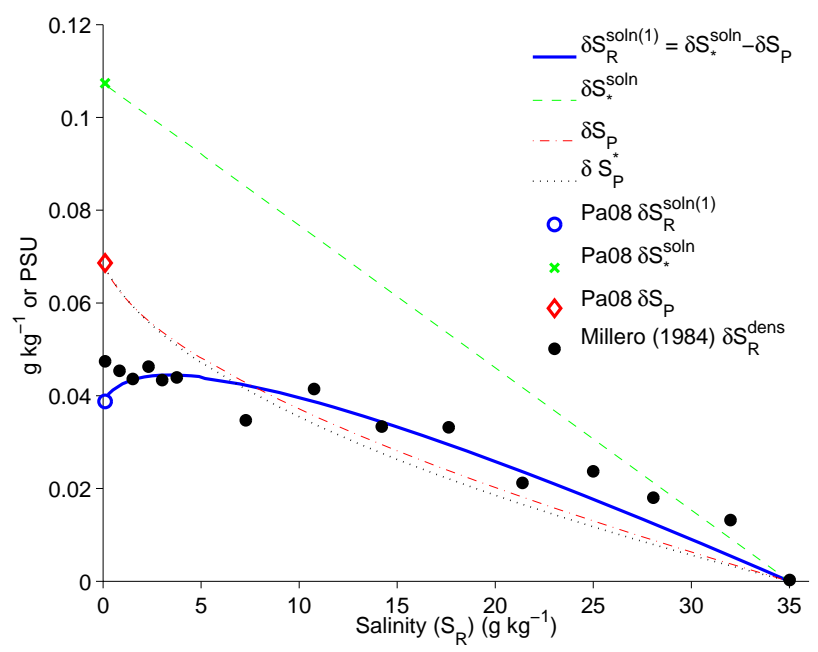

Fig. 8. Comparison between $\delta S_{\mathrm{R}}^{\mathrm{soln}(1)}$ computed with the full perturbation model in this paper with the measurements of $\delta S_{\mathrm{R}}^{\text {dens }}$ by Millero (1984) in mixtures of SSW and artificial river water. Also shown are direct estimates $\delta S_{\mathrm{P}}^{*}$ using the Pa08 model, as well as limiting case estimates for pure river water using $\mathrm{Pa} 08$.

perturbation in a fixed-chlorinity calculation. The name is somewhat misleading here because the river water also contains $\mathrm{Cl}^{-}$but this does not affect the mathematical details of the calculation. Calculations must be modified slightly when $S_{\mathrm{P}}<5$, since the usual seawater parameterizations of the carbonate equilibria are no longer valid in this low-salinity range. They do not extrapolate correctly to pure-water limits. Instead we use low-salinity parameterizations more suitable for river and lake waters (Millero, 1995). The change of $\delta S_{\mathrm{R}}^{\text {soln }}$ across the transition between the two regimes is not smooth, but the size of the step is small enough that it cannot be seen in Fig. 8 .

The $\delta S_{\mathrm{R}}^{\text {soln(1) }}$ arising from perturbation computations almost exactly lies within the scatter of the observations (Fig. 8). As salinity drops and the riverine addition becomes a larger fraction of the composition, $\delta S_{\mathrm{R}}^{\text {soln }}$ increases. One unexpected result is that $\delta S_{\mathrm{R}}^{\text {soln(1) }}$ increases roughly linearly with decreases in salinity only at high salinities. When $S_{\mathrm{R}}$ drops below about $10 \mathrm{~g} \mathrm{~kg}^{-1}, \delta S_{\mathrm{P}}$ curves upwards quite sharply, so that the $\delta S_{\mathrm{R}}^{\text {soln(1) }}$ curve flattens and even decreases at very low salinities. The observations do not appear to show this, although their scatter is large enough that this behavior cannot be ruled out. However, at low salinities where the Pa08 model is known to be accurate (unpublished results), it can be applied directly to $C_{\text {mixture }}$ and the alternative estimate $\delta S_{\mathrm{P}}^{*}$ used in place of the perturbation calculation for $\delta S_{\mathrm{P}}$. Results agree almost exactly with the perturbation model, showing the same curvature. Agreement is good at low salinities because the bias in Pa08 is small, and is good at high salinities because the river water perturbation is very small.
Table 4. Composition $C_{\mathrm{RW}}$ of artificial river water used by Millero (1984). Numbers have been adjusted to correct for typographical errors in Millero et al. (1976) and to agree best with stated values of both molar and mass concentrations in that paper, after rounding. TA is set by charge balance, with DIC carbonate ion concentrations computed from TA and $\mathrm{pH}$ using the low-salinity carbonate system parameterizations of Millero (1995) when $S_{\mathrm{P}}<5$.

\begin{tabular}{ll}
\hline Species & $\begin{array}{l}\text { Concentration } \\
\left(\mathrm{mmol} \mathrm{kg}^{-1}\right)\end{array}$ \\
\hline $\mathrm{Ca}^{2+}$ & 0.3745 \\
$\mathrm{Mg}^{2+}$ & 0.1685 \\
$\mathrm{Na}^{+}$ & 0.2740 \\
$\mathrm{~K}^{+}$ & 0.0590 \\
$\mathrm{SO}_{4}^{2-}$ & 0.1165 \\
$\mathrm{Cl}^{-}$ & 0.2200 \\
$\mathrm{NO}_{3}^{-}$ & 0.0160 \\
$\mathrm{HCO}_{3}^{-}$ & 0.9434 \\
$\mathrm{CO}_{3}^{2-}$ & 0.0031 \\
$\mathrm{CO}_{2}$ & 0.0440 \\
$\mathrm{OH}^{-}$ & 0.0004 \\
& \\
$\mathrm{pH}_{\mathrm{TA}}$ & 7.60 \\
$\mathrm{DIC}$ & $0.9500 \mathrm{meq} \mathrm{kg}^{-1}$ \\
$S_{\mathrm{A}}^{\text {soln }}$ & 0.9905 \\
\hline
\end{tabular}

Finally, for $a=0 \mathrm{~Pa} 08$ directly predicts a conductivity of $142 \mu \mathrm{S} \mathrm{cm}^{-1}$, which can then be used with PSS-78 to compute $S_{\mathrm{P}}=0.0686$ and hence $\delta S_{\mathrm{R}}^{\text {soln }}=0.0388 \mathrm{~g} \mathrm{~kg}^{-1}$ independently of the seawater perturbation model. The perturbation model does approach these values in the limit as $a \rightarrow 0$. Note however that this limit is not a good indicator of the zerosalinity intercept of a best-fit line through the observations, especially those from salinities $>5 \mathrm{~g} \mathrm{~kg}^{-1}$, typical of most estuarine waters, because of the curvature in $\delta S_{\mathrm{P}}$. Such a best fit line would intercept the left axis at rather higher values. Overall, however, although the particular chemistry of the oceanic perturbations may result in different errors than those associated with riverine dilutions, there do not appear to be any general biases present.

\section{Discussion and conclusions}

The combination of a chemical model of seawater and a conductivity model allows the effects of compositional perturbations on conductivity-based methods of salinity determination to be estimated. An immediate result is that conductivity itself is relatively insensitive to biogeochemical perturbations to the chemical composition of seawater. In fixed chlorinity calculations, $\delta S_{\mathrm{P}}$ increases by less than 0.007 over the range of waters investigated in the world ocean, while $S_{\mathrm{A}}^{\text {soln }}$ increases by up to $0.04 \mathrm{~g} \mathrm{~kg}^{-1}$. Numerical values of $S_{\mathrm{R}}$ 
(i.e. the scaled $S_{\mathrm{P}}$ ) lie somewhere between a chlorinity-based measure and the true absolute salinity, although much closer to the former. This also accounts for the stability of conductivity in SSW (Bacon et al., 2007), in spite of the known variations in DIC that occur within samples.

A second result is that the observed $\delta S_{\mathrm{R}}^{\text {soln }}$ are almost entirely explained by changes in nutrients and the carbonate system. Although this fact is already known empirically and is the basis for existing estimates of $\delta S_{\mathrm{R}}^{\text {dens }}$ (e.g., McDougall et al., 2009; Millero, 2000) the model calculations provide a more theoretical confirmation. In addition, the model shows that variations in $\mathrm{Ca}^{2+}$ and/or $\mathrm{SO}_{4}^{-}$are as important as changes in $\mathrm{NO}_{3}^{-}$, although they are linked via biogeochemical relationships.

Another result is that the effects of perturbations at typical oceanic salinities are approximately linear functions of salinity, but that this linear behavior does not extrapolate well to behavior at low salinities $\left(S_{\mathrm{P}}<5\right)$. At low salinities carbonate composition and $\delta S_{\mathrm{P}}$ become much more nonlinear functions of salinity. Thus generalizations based on infinite dilution quantities, or river endpoints, are qualitatively useful but may in practice be less relevant to oceanic situations than might be otherwise be expected. Conversely, extrapolations of linear fits to measurements in estuarine waters will not necessarily agree with observations of river end-members.

However, although the general agreement between calculated $\delta S_{\mathrm{R}}^{\text {soln }}$ and density-based estimates like $\delta S_{\mathrm{R}}^{\text {dens }}$ is good, differences remain. The differences are not very much larger than the typical uncertainty arising from density measurements, but are systematic. There are several possible explanations for these differences.

First, the Pa08 conductivity model may be inadequate to correctly calculate perturbations in this application. The scatter in comparisons between predictions and observations in Fig. 3 suggests that the model bias may still depend to some extent on chemical composition. It is difficult to fully address this issue without more data for comparison. However, the good agreement with the dataset on mixtures of artificial river water and seawater (Fig. 8) suggests that model performance is adequate in at least some cases, even when the perturbations become very large. Agreement between the fixed chlorinity calculation for $\delta S_{\mathrm{R}}^{\text {soln(1) }}$ (Eq. 27) and the fixed conductivity calculation for $\delta S_{\mathrm{R}}^{\text {soln(2) }}$ (Eq. 29) for the case of biogeochemical perturbations is also very good. The maximum difference between the two is only $0.0007 \mathrm{~g} \mathrm{~kg}^{-1}$. Since each calculation involves somewhat different changes to the chemical composition, and different assumptions about bias correction, this also suggests that these composition-dependent model errors are almost an order of magnitude smaller compared to the differences between model-estimated and density estimated salinity corrections.
Second, the overall comparison between the model and the other predictions in Fig. 7 can (perhaps) be improved by decreasing all calculated $\delta S_{\mathrm{R}}^{\text {soln }}$ by a small (constant) amount. Differences between the predictions will then be both positive and negative, instead of mostly positive. Constant increases or decreases will result from changes in the specified DIC content of SSW76. As discussed in Sect. 2.1 it is not possible at this time to precisely define the DIC content of SSW, and the appropriate value may have to be "tuned" to allow predictions and observations of $\delta S_{\mathrm{R}}^{\text {soln }}$ to match. The value used in this paper results in $\delta S_{\mathrm{R}}^{\text {soln }} \approx 0$ in the surface North Atlantic. However, reducing DIC in SSW76 to provide a better match in the North Pacific would result in a negative $\delta S_{\mathrm{R}}^{\text {soln }}$ in the surface North Atlantic.

A third possibility is that the biogeochemical model (Eq. 11) is in error. Imagine that instead of increasing $\mathrm{Ca}^{2+}$ by $\approx 100 \mu \mathrm{mol} \mathrm{kg}{ }^{-1} \mathrm{SO}_{4}^{2-}$ is decreased by a similar amount according to Eq. (12). Since these ions have different effects on conductivity, the change would decrease $\delta S_{\mathrm{R}}^{\text {soln }}$ in the North Pacific by as much as $0.007 \mathrm{~g} \mathrm{~kg}^{-1}$ from our present estimates, which would (again) account for much of the difference. Sulfate reduction may be an important process on shelves (and in anoxic basins), but its importance in the open ocean is less easy to determine.

Fourth, it is possible that these differences reflect inadequacies in the empirical algorithms of Millero (2000) and McDougall et al. (2009) used to calculate the corrections. The database of density measurements used to determine these different algorithms may simply not be large enough to correctly characterize the whole ocean and extrapolations to unsampled regions may not be completely valid. A more detailed comparison with the existing database of density measurements may help to resolve this issue.

A different and more fundamental explanation for disagreements, especially in the North Pacific, may be that the true correction $\delta S_{\mathrm{R}}^{\text {soln }}$ value calculated from our model might not be equivalent to the "effective" correction $\delta S_{\mathrm{R}}^{\text {dens }}$ computed from density measurements, which is merely chosen to produce the correct density when the equation of state is applied using salinity as a state variable. Agreement between the two estimates depends partly on the definition of salinity, and partly on the haline contraction coefficient being similar for perturbations with different composition.

The haline contraction coefficient is a measure of the density change related to a particular salinity change. The working assumption for McDougall et al. (2009) is that the density change arising from a given mass change will be insensitive to the composition of the change. The haline contraction coefficient is then calculated from the equation of state, equivalent to assuming that all constituents change in the proportions already found in seawater. This assumption has been shown to be true within practical limits for typical low-salinity river waters, and for mixtures of artificial river and seawaters (Millero, 1975). The agreement between 
the perturbation model and density-based measurements for the case of artificial river water mixtures (Fig. 8) also suggests that this is likely not a large factor at least in some cases. However, this previous work has not considered the full range of compositional variations, and, in particular, the biogeochemical perturbations in seawater.

Biogeochemical perturbations involve nutrients, carbonates, and dissolved gases. Perhaps fortuitously, changes in the concentrations of the dissolved gases (which for $\mathrm{O}_{2}$ in particular are well above the $1 \mathrm{mg} \mathrm{kg}^{-1}$ threshold) have virtually no effect of density (Watanabe and Iizuka, 1985). Thus their neglect in the usual definition of salinity has not been important in the past. However, the haline contraction coefficient for $\mathrm{Si}(\mathrm{OH})_{4}$ at least is slightly less than half of that for typical ions in natural freshwaters and seawaters (Wüest et al., 1996). That is, the density change resulting from a given change in the mass of $\mathrm{Si}(\mathrm{OH})_{4}$ is slightly less than half that for a change of the same mass of the typical ions in natural waters. Thus density measurements converted to mass changes using a haline contraction coefficient derived from the density equation will underestimate the true salinity variation arising from silicate addition. Investigation of this issue should be possible using an appropriate model for density.

An additional issue is that the definition of salinity $S_{\mathrm{A}}^{\text {soln }}$ (Eq. 2), although apparently straightforward, is not completely suitable for the purpose of quantifying small compositional changes in the ocean. Chemical reactions within seawater mean that the chemical formulas for ions present are not identical to the solids added. Si is actually added to seawater in the form of $\mathrm{SiO}_{2}$ which then dissolves and combines with $\mathrm{H}_{2} \mathrm{O}$, so the appropriate weighting factor for $\mathrm{Si}(\mathrm{OH})_{4}$, say in Eq. (32), may be the molar mass of $\mathrm{SiO}_{2}$, $\left(60.08 \mathrm{~g} \mathrm{~mol}^{-1}\right)$ rather than that of $\mathrm{Si}(\mathrm{OH})_{4}$. That is, the added $2 \mathrm{H}_{2} \mathrm{O}$ may be inappropriately included in the estimate of the mass of dissolved solids. Thus the calculated $\delta S_{\mathrm{R}}^{\text {soln }}$ overestimates the actual salinity change.

Reducing the $\mathrm{Si}(\mathrm{OH})_{4}$ coefficient in Eq. (32) in this way reduces $\delta S_{\mathrm{R}}^{\text {soln }}$ by $0.006 \mathrm{~g} \mathrm{~kg}^{-1}$ in our model NPIW (Table 3 ) and removes much of the difference in the North Pacific at depths greater than $2000 \mathrm{~m}$ (Fig. 7). However, other factors must also be important because there are only very small changes in predictions for the Arctic and North Atlantic, or indeed in any profile at depths shallower than $1000 \mathrm{~m}$. Changes in the Southern Ocean are larger, but still not sufficient to completely explain the differences.

A similar argument may be made for the mass of $\mathrm{NO}_{3}^{-}$, which results from the remineralization of organic $\mathrm{N}$ and and is therefore associated with a decrease in $\mathrm{O}_{2}$ already present in the water column. The dissolved gas $\mathrm{O}_{2}$ is not included in the definition of salinity, but when these atoms combine with $\mathrm{N}$ their mass then becomes part of the calculated salinity. However, the resulting changes in calculated salinity due to this inconsistency are only $0.002 \mathrm{~g} \mathrm{~kg}^{-1}$ for model NPIW, relatively small compared to those that arise from Si reactions.
Larger corrections arise from consideration of the $\mathrm{O}_{2}$ and $\mathrm{H}_{2} \mathrm{O}$ that accompany the dissolution of organic carbon and its conversion to carbonates. In model NPIW the DIC increase is $300 \mu \mathrm{mol} \mathrm{kg}-1$ and the carbonate component of $S_{\mathrm{A}}^{\text {soln }}$ increases by $0.018 \mathrm{~g} \mathrm{~kg}^{-1}$ (Table 3) using the definition of Eq. (2). However, the true added mass of dissolved carbonrelated material, partly remineralized organic $\mathrm{C}$ and partly $\mathrm{CO}_{3}^{-}$from dissolved $\mathrm{CaCO}_{3}$, is only $0.008 \mathrm{~g} \mathrm{~kg}^{-1}$. Remineralization involves the combination of $0.0025 \mathrm{~g} \mathrm{~kg}^{-1}$ of organic $C$ with almost $0.007 \mathrm{~g} \mathrm{~kg}^{-1}$ of $\mathrm{O}_{2}$ to produce $\mathrm{CO}_{2}$. The remainder of the discrepancy is due to the dissolution of $\mathrm{H}_{2} \mathrm{O}$ in the chemical reactions governing the carbonate equilibria.

Thus it is possible that by rewriting the definition for the absolute salinity of compositional perturbations, to more precisely reflect the actual addition of dissolved material, the numerical values for $\delta S_{\mathrm{R}}^{\text {soln }}$ can be made smaller by as much as $0.018 \mathrm{~g} \mathrm{~kg}^{-1}$ for NPIW. This can be accomplished without any change in the actual composition, conductivity, or density of the water. Such a variation is more than enough to account for the observed differences. Again, a more detailed comparison with measured $\delta S_{\mathrm{R}}^{\text {dens }}$ would be required to determine whether this would be useful. One drawback of this approach is that such a redefinition would involve specifying the biogeochemical processes involved, which would make the result less general. In addition, including $\mathrm{O}_{2}$ decreases in the definition of salinity perturbations, but not in the definition of $S_{\mathrm{A}}^{\text {soln }}$ itself, could create other inconsistencies.

The differences do not arise because the temperature of calculations was set at $25^{\circ} \mathrm{C}$, even though in-situ conductivities used to determine observations of $S_{\mathrm{P}}$ are generally measured at much lower temperatures. Conductivity is highly temperature-dependent, and this dependence varies with composition. For SSW, changes in temperature will not result in a change in $S_{\mathrm{P}}$ because the PSS-78 formula (Eq. 1) accounts for the effects of temperature variations. However, the temperature effect is slightly different for perturbed compositions. The correction factor $\tau$ when comparing conductivities at $25^{\circ}$ to those at a temperature $\theta$, defined as:

$$
\frac{\kappa\left(\beta C_{0}+\delta C_{*}, 25^{\circ} \mathrm{C}\right)}{\kappa\left(\beta C_{0}+\delta C_{*}, \theta\right)}=\frac{\kappa\left(C_{0}, 25^{\circ} \mathrm{C}\right)}{\kappa\left(C_{0}, \theta\right)} \cdot(1+\tau)
$$

can be estimated using $\kappa_{\mathrm{Pa} 08}$ for $\kappa$. For $\delta C_{*}$ representing model NPIW, and $\theta=1^{\circ} \mathrm{C}, \tau \approx-1 \times 10^{-5}$, which changes $\delta S_{A}$ by less than $-0.0004 \mathrm{~g} \mathrm{~kg}^{-1}$. This is negligible relative to the other effects discussed above.

Although the temperature effect is not important, we cannot determine at present which (if any) of the other possible explanations is most important in resolving the differences. However, it appears more likely that they result from uncertainties in the chemical model and/or the definition of salinity rather than from any fundamental problems with the conductivity calculation. It will be important to model density as well as conductivity to fully understand the source of these differences in ocean observations. 
In summary, although conductivity measurements have been of primary importance to oceanographic studies for at least a generation our knowledge of the relationship between conductivity and salinity has been purely empirical. There remain many uncertainties about the reliability and predictability of standard procedures. Development of a theory with which variations can be studied is therefore potentially important for studies in many different areas.

For example, it has been shown here that biogeochemical processes have a measurable effect on the conductivity/salinity relationship. This suggests that comparisons between more comprehensive datasets of direct density measurements and our predictions may be useful in constraining future research into these processes. Even in the shallow ocean, the changing composition due to changes in atmospheric $\mathrm{CO}_{2}$ may affect salinity estimates and this model provides a way of investigating the effects of such changes. In coastal and estuarine systems, compositional variations are known to affect density and other properties (e.g. Millero et al., 1976). Comparisons of density and $S_{\mathrm{P}}$ measurements may then be useful in estimating the pools (and eventually residence times) of the constituents of these variations.

In addition to these purely scientific concerns, the availability of this theory may be useful in solving a number of technical issues arising in current practices. The extrapolation of $\delta S_{\mathrm{R}}^{\text {dens }}$ estimates into waters for which no density measurements are available (as done by McDougall et al. (2009) to provide correction factors in coastal and Arctic regions) can be confirmed if information is available about compositional perturbations. The effects of pressure, which can lead to small changes in the chemical equilibria of the carbonate system, can also be investigated. Finally, there are possible uncertainties in the reliability of SSW for highest precision measurements (Kawano et al., 2006), although it is unclear why these variations arise (Bacon et al., 2007). Again, the model developed here may be useful in resolving some of these technical issues.

Acknowledgements. Dan Wright (Dept. of Fisheries and Oceans, Canada) provided the initial impetus for this work by suggesting that the Pa08 model could be used to linearize about a standard seawater base state. In addition, I would like to thank the members of SCOR WG-127 providing useful advice. Debby Ianson (Dept. of Fisheries and Oceans, Canada) carried out the DIC analyses for old batches of SSW. This work was supported by the Natural Sciences and Engineering Research Council of Canada under grant 194270-06.

Edited by: R. Feistel

\section{References}

Bacon, S., Culkin, F., Higgs, N., and Ridout, P.: IAPSO Standard Seawater: Definition of the Uncertainty in the Calibration Procedures and Stability of Recent Batches, J. Atmos. Ocean. Tech., 24, 1785-1799, 2007.
Brewer, P. G. and Bradshaw, A.: The effect of the non-ideal composition of seawater on salinity and density, J. Mar. Res., 33, 157-175, 1975.

Chen, C.-T. A.: Shelf-vs. dissolution-generated alkalinity above the chemical lysocline, Deep-Sea Res. Pt. II, 49, 5365-5375, 2002.

Conners, D. N. and Kester, D. R.: Effect of the major ion variations in the marine environment on the specific gravity-conductivitychlorinity-salinity relationship, Mar. Chem., 2, 301-314, 1974.

Conners, D. N. and Park, K.: The partial equivalent conductances of electrolytes in seawater: a revision, Deep-Sea Res., 14, 481-484, 1967.

Conners, D. N. and Weyl, P. K.: The partial equivalent conductances of salts in seawater and the density/conductance relationship, Limnol. Oceanogr., 13, 39-50, 1968.

Corti, H., Crovetto, R., and Fernández-Prini, R.: Mobilities and Ion-Pairing in $\mathrm{LiB}(\mathrm{OH})_{4}$ and $\mathrm{NaB}(\mathrm{OH})_{4}$ Aqueous Solutions. A Conductivity Study, J. Solution Chem., 9, 617-625, 1980.

de Villiers, S.: Excess dissolved Ca in the deep ocean: a hydrothermal hypothesis, Earth Planet. Sc. Lett., 164, 627-641, 1998.

de Villiers, S. and Nelson, B. K.: Detection of Low-Temperature Hydrothermal Fluxes by Seawater $\mathrm{Mg}$ and $\mathrm{Ca}$ Anomalies, Science, 285, 721-723, 1999.

Dickson, A. G., Sabine, C. L., and Christian, J. R. (Eds.): Guide to best practices for ocean $\mathrm{CO}_{2}$ measurements, PICES Special Publication 3, 2007.

Feistel, R.: A Gibbs function for seawater thermodynamics for -6 to $80^{\circ} \mathrm{C}$ and salinity up to $120 \mathrm{~g} \mathrm{~kg}^{-1}$, Deep-Sea Res. Pt. I, 55, 1639-1671, 2008.

Goyet, C., Poisson, A., Brunet, C., and Culkin, F.: IAPSO Standard Seawater as a reference standard for alkalinity determinations, Deep-Sea Res., 32, 1437-1443, 1985.

Hall, K. J. and Northcote, T. G.: Conductivity-Temperature standardization and dissolved solids estimation in a meromictic saline lake, Can. J. Fish. Aquat. Sci., 43, 2450-2454, 1986.

Hill, K. D., Dauphinee, T. M., and Woods, D. J.: The Extension of the Practical Salinity Scale 1978 to Low Salinities, IEEE J. Oceanic Eng., OE-11, 109-112, 1986a.

Hill, K. D., Dauphinee, T. M., and Woods, D. J.: A comparison of the Temperature Coefficients of Electrical Conductivity of Atlantic and Pacific Seawaters, IEEE J. Oceanic Eng., OE-11, 485486, 1986 b.

Jellison, R., Macintyre, S., and Millero, F. J.: Density and conductivity properties of $\mathrm{Na}-\mathrm{CO}_{3}-\mathrm{Cl}-\mathrm{SO}_{4}$ brine from Mono Lake, California, USA, Int. J. Salt Lake Res., 8, 41-53, 1999.

Kawano, T., Aoyama, M., Joyce, T., Uchida, H., Takatsuki, Y., and Fukasawa, M.: The Latest batch-to-batch Difference Table of Standard Seawater and Its Application to the WOCE Onetime Sections, J. Oceanogr., 62, 777-792, 2006.

Lewis, E. L. and Perkin, R. G.: Salinity: Its definition and Calculation, J. Geophys. Res., 83, 466-478, 1978.

McDougall, T. J., Jackett, D. R., and Millero, F. J.: An algorithm for estimating Absolute Salinity in the global ocean, Ocean Sci. Discuss., 6, 215-242, 2009,

http://www.ocean-sci-discuss.net/6/215/2009/.

Millero, F. J.: The Physical Chemistry of Estuaries, in: Marine Chemistry in the Coastal Environment, edited by: Church, T. M., American Chemical Society, 25-55, 1975.

Millero, F. J.: The conductivity-density-salinity-chlorinity relationships for estuarine waters, Limnol. Oceanogr., 29, 1317-1321, 
1984.

Millero, F. J.: Thermodynamics of the carbon dioxide system in the oceans, Geochim. Cosmochim. Ac., 59, 661-677, 1995.

Millero, F. J.: Effect of changes in the composition of seawater on the density-salinity relationship, Deep-Sea Res. Pt. I, 47, 15831590, 2000.

Millero, F. J. and Poisson, A.: International one-atmosphere equation of state for seawater, Deep-Sea Res., 28A, 625-629, 1981.

Millero, F. J., Lawson, D., and Gonzalez, A.: The Density of Artificial River and Estuarine Waters, J. Geophys. Res., 81, 11771179, 1976.

Millero, F. J., Zhang, J. Z., Lee, K., and Campbell, D. M.: Titration alkalinity of seawater, Mar. Chem., 44, 153-165, 1993.

Millero, F. J., Feistel, R., Wright, D. G., and McDougall, T. J.: The composition of Standard Seawater and the definition of the Reference-Composition Salinity Scale, Deep-Sea Res. Pt. I, 55, 50-72, 2008.

Nozaki, Y.: A fresh look at element distribution in the North Pacific Ocean, EOS, Transactions American Geophysical Union, 78, 221-221, doi:10.1029/97EO00148, 1997.

Park, K.: Partial equivalent conductance of electrolytes in seawater, Deep-Sea Res., 11, 729-736, 1964.

Pawlowicz, R.: Calculating the conductivity of natural waters, Limnol. Oceanogr-Meth., 6, 489-501, 2008.

Perkin, R. G. and Lewis, E. L.: The Practical Salinity Scale 1978: Fitting the Data, IEEE J. Oceanic Eng., OE-5, 9-16, 1980.
Poisson, A., Périé, M., Périé, J., and Chemla, M.: Individual equivalent conductances of the major ions in seawater, J. Solution Chem., 8, 377-394, 1979.

Sarmiento, J. L. and Gruber, N.: Ocean Biogeochemical Dynamics, Princeton University Press, Princeton, 2006.

Soffyn-Egli, P. and Mackenzie, F. T.: Mass balance of dissolved lithium in the oceans, Geochim. Cosmochim. Ac., 48, 859-872, 1984.

Unesco/ICES/SCOR/IAPSO joint panel on oceanographic tables and standards: Background papers and supporting data on the Practical Salinity Scale 1978, Unesco technical papers in marine science 37, 1981.

Vollmer, M. K., Weiss, R. F., Williams, R. T., Falkner, K. K., Qiu, X., Ralph, E. A., and Romanovsky, V. V.: Physical and chemical properties of the waters of saline lakes and their importance for deep-water renewal: Lake Issyk-Kul, Kyrgyzstan, Geochim. Cosmochim. Ac., 66, 4235-4246, 2002.

Watanabe, H. and Iizuka, K.: The influence of dissolved gases on the density of water, Metrologia, 21, 19-26, 1985.

Wüest, A., Piepke, G., and Halfman, J. D.: Combined effects of dissolved solids and temperature on the density stratification of Lake Malawi, in: The Limnology, Climatology, and Paleoclimatology of the East African Lakes, edited by: Johnson, T. C. and Odada, E. O., Gordon and Breach, Australia, 183-204, 1996. 